\title{
Criterios de la carga de la prueba respecto de los costos y deducciones en el impuesto de renta*
}

\section{Criteria of the Burden of Proof about Costs and Deductions in the Income Tax}

\author{
EVELIN LISET LUQUEZ RIVERA ${ }^{1}$
}

\section{Sumario}

Introducción. I. La carga de la prueba. Desarrollo dogmático y jurídico. A. El rol del juez en la carga de la prueba. Sistemas fundamentales para la regulación de la prueba judicial y su aplicación en el Estado Social de Derecho. B. Las normas jurídicas que regulan la carga de la prueba en los procedimientos y procesos administrativos tributarios. II. Jurisprudencia del Consejo de Estado en materia de la carga de la prueba de los costos y deducciones. A. Jurisprudencia del Consejo de Estado sobre la carga de la prueba en vía administrativa. B. Jurisprudencia del Consejo de Estado sobre la carga de la prueba en sede judicial. III. Valoración y agrupación de las reglas de la carga de la prueba de los costos y deducciones, identificadas en la normativa tributaria y procesal, y en la juris- prudencia. A. Regla general: el criterio de la carga afirmativa. B. Excepción a la regla general: la carga dinámica de la prueba, la carga de la duda probatoria y la regla de la no carga de la prueba de los hechos aceptados por los contribuyentes en las respuestas. IV. Conclusiones. Bibliografía.

\section{Resumen}

En el artículo son analizados los criterios de la carga de la prueba en los costos y deducciones, que lleva a la concreción de ciertas reglas que muestran la dinámica probatoria que se despliega en el procedimiento tributario y en el proceso contencioso administrativo y que, a la vez, revela la posibilidad de que se produzca una consecuencia negativa por la falta de responsabilidad probatoria.

* DOI: https://doi.org/10.18601/16926722.n11.02

${ }^{1}$ Abogada de la Universidad Libre, con especialización en Derecho tributario, de la Universidad de Rosario, y candidata a magíster en Derecho con énfasis en tributación, de la Universidad Externado de Colombia, con amplia experiencia en la rama judicial. Actualmente se desempeña como Profesional Especializado Grado 33 de la Sección Cuarta del Consejo de Estado. Correo-e: evelinluquez@outlook.com. 
Para tal efecto, se presenta un análisis de las normas procesales y tributarias que establecen la responsabilidad probatoria del contribuyente y de la Administración, y un estudio que pone de manifiesto el criterio jurisprudencial que ha desarrollado el Consejo de Estado en materia de la carga de la prueba.

Todo ello llevó a que se identificara un criterio general de la carga de la prueba, que consiste en el sistema dispositivo, y unas reglas excepcionales relativas a la carga dinámica de la prueba y a la prevista en el artículo 745 del Estatuto Tributario.

Dicho análisis, en particular el referente al artículo 745 ibídem, permitió que en este escrito se concluyera que en el procedimiento tributario administrativo existe la carga de la prueba con su correlativa consecuencia negativa y, en ciertos casos, se permite la aplicación de la carga dinámica de la prueba.

Palabras clave: Carga de la prueba, Carga dinámica de la prueba, Sistema dispositivo e inquisitivo, Dudas por vacíos probatorios, Precedente jurisprudencial, Costos y deducciones.

\begin{abstract}
The article makes an analysis of the criteria of the burden of proof in costs and deductions, which leads to the realization of certain rules that show the probative dynamics that unfold in the tax procedure and in the administrative contentious process, and that It reveals the possibility of a negative consequence due to the lack of evidentiary responsibility. To this end, an analysis of
\end{abstract}

the procedural and tax rules that establish the probative responsibility of the taxpayer and the Administration, and a study that highlights the jurisprudential criterion developed by the Council of State in the matter of the burden of proof. All this led to the identification of a general criterion of the burden of proof consisting of the device system and exceptional rules relating to the dynamic loading of evidence and to that provided for in article 745 of the Tax Statute. This analysis, in particular, the one referring to article $745 \mathrm{ibid}$, allowed that in this writing it was concluded that in the administrative tax procedure there is the burden of proof with its correlative negative consequence and, in certain cases, the application of the burden is allowed test dynamics.

Keywords: Burden of Proof, Fundamental Systems for the Regulation of Judicial Evidence, Tax Administrative Procedures and Processes, Tax Rules.

\section{Introducción}

El presente artículo estudiará la forma como la ley tributaria ha repartido la carga de la prueba de los costos y deducciones en el impuesto de renta, y la manera como la misma ha sido aplicada e interpretada por la jurisdicción contencioso administrativa, en particular por la Sección Cuarta del Consejo de Estado.

El estudio responde a la necesidad de establecer que, en el caso colombiano, existe realmente la carga de la prueba en materia tributaria, teniendo en cuenta que autores como Zornoza Pérez (2006, p. 35) señalan que la consecuencia jurídica que esa carga 
implica no se presenta en los procedimientos administrativos tributarios ${ }^{2}$.

En esa tarea, se concretarán ciertos criterios de aplicación de la carga de la prueba cuando se trata de conceptos que aminoran la carga tributaria, tales como los costos y deducciones, para efectos de suministrar una herramienta que aporte a una de las problemáticas que se presentan en los procedimientos y procesos tributarios, concerniente a la determinación de la obligación tributaria ante la existencia de incertidumbre de los hechos discutidos.

En efecto, en el procedimiento tributario, aun cuando la Administración cuenta con amplias facultades inquisitivas para determinar la obligación tributaria, como las pruebas de oficio y las estimaciones y presunciones, existe conflicto entre aquella y los contribuyentes, frente a la decisión administrativa que recae sobre dudas por vacíos probatorios.

Por su parte, en el proceso contencioso administrativo, una de las principales dificultades que encuentran los jueces al momento de proferir la sentencia es la imposibilidad de alcanzar una determinación verdadera de los hechos en el proceso, como ocurre ante la falta de la prueba que soporta los costos y deducciones en el impuesto de renta. Esa situación hace necesario que los operadores judiciales acudan a la aplicación de las reglas de la carga de la prueba establecidas en las normas jurídicas y desarrolladas en la jurisprudencia, e impongan a la parte respectiva la consecuencia negativa que de ella se deriva, a fin de tomar una decisión de fondo en el supuesto de incertidumbre sobre los hechos. Jurisprudencia que, aunque en materia administrativa, solo constituye precedente obligatorio para las autoridades cuando es unificada por el Consejo de Estado ${ }^{3}$, no puede desconocerse que en los demás casos la misma orienta la interpretación y aplicación de las normas jurídicas por parte de los despachos judiciales, más aun si se trata de la expedida por el máximo órgano de la jurisdicción de lo contencioso administrativo.

Es por esas razones que en este artículo se analizan las sentencias proferidas por el Consejo de Estado, que permiten identificar los criterios sobre la carga de la prueba que son aplicados por la jurisdicción para resolver las controversias relativas a los costos y deducciones. Para lo cual, se presenta una selección de la jurisprudencia proferida por el Consejo de Estado durante los años 2009 a 2017, que consideramos como las más

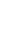


relevantes para entrever la visión de esa corporación en la aplicación de la carga de la prueba en materia de costos y deducciones.

Tratándose la carga de la prueba de un principio del Derecho procesal, el análisis se hará de forma concomitante con las normas generales de Derecho probatorio aplicable a los procedimientos y el proceso administrativo tributario, como las contenidas en el CPACA y el Código General del Proceso. Así mismo, se tendrá en cuenta la doctrina de autores de Derecho civil, administrativo y tributario.

El estudio de las normas jurídicas y las citadas providencias se realiza a partir de determinados supuestos fácticos que se presentan en el procedimiento tributario, en los que se puede constatar de una mejor manera la responsabilidad de las partes en la aportación y contradicción de la prueba, y la dinámica de la carga probatoria en cada etapa procesal, como aquellos casos en los que el contribuyente presenta la declaración, cuando no la presenta y cuando está o no obligado a llevar contabilidad, así como en los eventos de las inspecciones, requerimientos ordinarios, indicios, presunciones, estimaciones, circunstancias especiales que deben probarse por el contribuyente y dudas por vacíos probatorios, y la aplicación de esa carga probatoria en sede judicial. Supuestos fácticos que permitirán identificar la existencia de reglas de la carga de la prueba en las normas jurídicas y en el precedente jurisprudencial, así como la explicación de sus contornos.

Todo, para concretar los criterios sobre la distribución de la carga de la prueba en los que se verificará que los escenarios de responsabilidad son múltiples y, dependiendo de algunos casos, dicha carga puede variar. Lo que permitirá plantear una interpretación sobre el artículo 745 del Estatuto Tributario y su alcance en materia de la carga de la prueba, que llevará a que en este escrito se concluya que en el procedimiento tributario colombiano no solo existe la carga de la prueba, sino que también se aplica la "carga dinámica" en ciertos eventos.

\section{La carga de la prueba. Desarrollo dogmático y jurídico}

Los procesos, en general, inician con la finalidad de dar reconocimiento y efectividad a un derecho y, por ende, la ley impone a las partes la autorresponsabilidad de ejercer determinadas conductas en su trámite, la cual se ha denominado de forma general como carga procesal. Se hace referencia al término autorresponsabilidad porque, como lo sostienen autores como Micheli y Rosenberg citados por Deivis Echandía (2012, pp. 377-379), "la carga procesal es una responsabilidad de las partes, no un deber ni una obligación, puesto que de no ejercerse no existe coacción o sanción, sino que la consecuencia es que no se produciría el fin jurídico que estas persiguen"4.

\footnotetext{
${ }^{4}$ Deivis Echandía también señaló que "la carga implica una actividad que es siempre voluntaria aun cuando el dejar de cumplirla implique efectos perjudiciales al sujeto; no impone un deber ni una obligación, pues de lo contrario sería necesario decir que cada parte tiene el deber de triunfar, y esto es inaceptable, ya que solo el propio interés da impulso para actuar". De ahí que concluyera que el resultado favorable de la inobservancia no es considerado como una sanción, ni siquiera económica, sino como el efecto natural de la aplicación de la norma positiva que establece la carga.
} 
Para efectos de este estudio, interesa señalar que dentro del concepto de carga procesal se encuentra el onus probandi o la carga de la prueba, consagrada como un principio general del Derecho procesal que tiene por objeto establecer quién debe probar y qué sucede cuando no se prueban los hechos discutidos en un proceso.

Como destaca Parra Quijano (2014, p. 232), "la carga de la prueba es una noción procesal que consiste en una regla de juicio, que les indica a las partes la autorresponsabilidad que tienen para que los hechos que sirven de sustento a las normas jurídicas cuya aplicación reclaman aparezcan demostrados y que, además le indican al juez cómo debe fallar cuando no aparezcan probados tales hechos".

En esa definición se vislumbran los dos aspectos que comprenden la carga de la prueba: el subjetivo y el objetivo. De acuerdo con Devis Echandía (2012, pp. 408-410), el aspecto subjetivo hace referencia a que la carga de la prueba contiene una norma de conducta para las partes que les informa los hechos que deben probar, para lograr el reconocimiento del derecho y evitar la pérdida del proceso. Y el aspecto objetivo se trata de una regla general de juicio que permite la decisión de fondo del proceso a pesar de la incertidumbre de los hechos que dieron origen al mismo. Es decir, permite dirimir un proceso que versa sobre un hecho incierto o desconocido.

En tal sentido, Rosenberg (1956, pp. 2 y 13) explica que si el juez al examinar las afirmaciones de las partes persiste en la incertidumbre sobre los hechos de la demanda, debe acudir a la regla de la carga de la prueba, porque esta le indica la forma de decidir en esos casos. Todo, porque el juez debe siempre afirmar o negar la consecuencia jurídica pedida en las pretensiones de la demanda. Lo anterior, agrega ese autor, porque la función de la normas sobre la carga de la prueba consiste, precisamente, en evitar eso -el non liquet-, "el no está claro o la expedición de un fallo inhibitorio". "La incertidumbre acerca de una afirmación no hace imposible el fallo sino que el juez, en este caso, debe fallar en contra de la parte que soporta la carga de la prueba".

Por lo anterior puede concluirse que la carga de la prueba, vista desde su carácter general, es una regla que únicamente opera en casos de incertidumbre probatoria, informando quién debió probar y, por ende, sufre la consecuencia negativa por los vacíos probatorios de los hechos discutidos en un proceso. Bajo ese contexto, se procede a analizar los sistemas del Derecho procesal utilizados para la aplicación de la carga de la prueba y la forma como estos se vislumbran en la Constitución Política de 1991.

\section{A. El rol del juez en la carga de la prueba. Sistemas fundamentales para la regulación de la prueba judicial y su aplicación en el Estado Social de Derecho}

Como se observa, el marco de acción del juez en materia la carga de la prueba está definido en determinar la parte que soporta la consecuencia negativa ante la existencia de incertidumbre por falta de prueba. Para tal efecto, el juez puede actuar con base en dos sistemas: (i) el dispositivo y (ii) el inquisitivo. 
El sistema dispositivo asigna a las partes, y no al juez, la iniciación e impulso del proceso, y la aportación de las pruebas. Bajo este sistema, Devis Echandía H. (2012, pp. 7172) destaca que el juez no cumple un papel activo. Esto se debe a que el sistema tiene por principal característica que las partes son las que tienen la facultad de disponer del elemento probatorio y que la sentencia debe limitarse a las peticiones del actor -principio de congruencia-. Por su parte, el sistema inquisitivo le otorga facultades al juez en diversos aspectos: impulso procesal y recaudación de las pruebas. Lo fundamental de este principio es la facultad oficiosa probatoria del juez. Aunque la aplicación del sistema inquisitivo en los procesos de carácter privado encontró cierta resistencia, autores como Betancur Jaramillo (1982, p. 130) y Devis Echandía H. (2012, p. 71-72), entre otros, sostienen que este sistema no desconoce el principio de igualdad de las partes ni de imparcialidad del juez, dado el interés público que tiene la jurisdicción de que los resultados de los litigios sean legales y justos.

Con la nueva concepción del Estado Social de Derecho de la Constitución Política de 1991, se concibe al juez como el protector de los derechos de las partes, en particular, cuando la actividad de las mismas no es suficiente para probar los hechos en disputa. Es así como la nueva Carta Política introdujo normas que contemplan las características del sistema dispositivo y del inquisitivo, así como también fortaleció la función del juez, en particular la relativa a los poderes oficiosos. Es decir, establece un modelo mixto.

Así, el sistema inquisitivo se vislumbra en el preámbulo de la Constitución cuando señala el próposito de asegurar la justicia dentro de un marco jurídico social justo, en el artículo 29 que establece el derecho fundamental al debido proceso, en el 228 que instituye la justicia como una función pública, y en el artículo 229 que establece el acceso a la administración de justicia como un derecho fundamental. En estas normas se robustece las función del juez al darle la condición de garante de la tutela efectiva ${ }^{5}$, lo que supone que por mandato constitucional el juez tiene facultades oficiosas para la distribución de las cargas procesales.

Adicionalmente, en el artículo 83 de la Constitución también se entrevé el sistema dispositivo, al consagrar que las actuaciones de los particulares deben ceñirse a los postulados de la buena fe, y en el artículo 95 que dispone como deber de las personas: el respeto de los derechos ajenos, el no abuso de los propios y la colaboración con el buen funcionamiento de la administración de justicia. Estas normas imponen a las personas el ejercicio adecuado de sus derechos, entre ellos, el derecho fundamental al acceso a la administración de justicia. Además, les impone el deber de colaborar con el buen funcionamiento de la justicia, y de realizar los actos procesales con buena fe.

\footnotetext{
${ }^{5}$ Derecho fundamental, que se traduce en la posibilidad de toda persona de poder acudir en condiciones de igualdad ante los jueces, por la debida protección o el restablecimiento de sus derechos e intereses legítimos, con plena observancia de las garantías sustanciales y procedimentales previstas en la ley. Definición extraída de la sentencia de la Corte Constitucional C-086 de 2016.
} 
En tal sentido, se puede concluir que la Carta no solo consagra para el juez prerrogativas de carácter inquisitivas u oficiosas para llegar a la verdad real, sino que también les impone a las partes el deber de actuar con diligencia y asumir las cargas procesales, entre estas, la carga de probar, principios que, en general, deben orientar la carga de la prueba en los procedimientos administrativos y los procesos judiciales, que de forma particular se pasa a precisar.

\section{B. Las normas jurídicas que regulan la carga de la prueba en los procedimientos y procesos administrativos tributarios}

La prueba en el Derecho tributario tiene por objeto demostrar la ocurrencia de un hecho gravable y, por consiguiente, en qué cuantía se encuentra gravado. Todo, para establecer la procedencia de la aplicación de las normas que determinan la obligación tributaria en cada caso concreto.

Esta actividad probatoria se da en el marco de dos escenarios: el procedimiento administrativo tributario y el proceso administrativo tributario, que a continuación serán objeto de análisis para efectos de identificar las normas que se han expedido en materia de aportación de prueba, y si esas disposiciones contemplan consecuencias jurídicas adversas por la falta de la misma, dadas las marcadas diferencias de naturaleza y regulación en esos trámites procesales.

\section{Normas del Estatuto Tributario sobre la carga de la prueba en el procedimiento administrativo tributario}

Según se ha dicho, el procedimiento busca la efectividad de los derechos. En el caso del
Derecho tributario, la ley dispuso un procedimiento especial seguido por la Administración Tributaria, que en Colombia es ejercida por la U.A.E. DIAN, con la finalidad de determinar y recaudar la obligación tributaria.

En ese contexto, Piza Rodríguez (2013, p. 517) aporta la siguiente clasificación de las etapas del procedimiento de aplicación o determinación de los tributos: a) Declaración por parte de los administrados; b) Procedimiento de gestión que comprendería a su vez tres sub-etapas: fiscalización, determinación o liquidación de los impuestos y recaudo, y c) El procedimiento de discusión o impugnación administrativo de los actos de la administración tributaria.

Para el presente estudio, interesa señalar que el impuesto de renta se liquida con el sistema de auto liquidación. Es decir, el procedimiento se estructura a partir de la declaración del contribuyente, realizada en cumplimiento de un deber formal de colaboración, en la que acepta la obligación tributaria y establece su cuantía, y la Administración cumple la función de comprobación de los hechos que dan lugar o aminoran la obligación tributaria y cuantía declaradas. A excepción de aquellos casos en los que el obligado tributario no cumpla con ese deber, evento en el cual la Administración iniciará el procedimiento con un acto administrativo.

Piza Rodríguez (2016, p. 241) señala que una particularidad muy importante es que, en estos procedimientos, la Administración no prueba, sino que comprueba que hayan tenido lugar los hechos que generan la obligación tributaria y determinan su cuantificación. Es por eso que en materia tributaria se habla de prueba en sentido impropio. A esa 
conclusión llegó el autor con fundamento en tres argumentos: no interviene un juez, esto es, un tercero que resuelva la controversia; no hay alteridad, pues la Administración es la que produce las pruebas y decide la controversia, a pesar de ser parte interesada, y el contexto del procedimiento está precedido por los deberes de colaboración del contribuyente, siendo el más importante la presentación de la declaración. Esa situación, la falta de alteridad, puede generar dudas en cuanto a la imparcialidad de la Administración, aun cuando esta actúa en representación del Estado y, por ende, en defensa del interés general. Ello por cuanto el contribuyente se encuentra en una situación de desventaja en tanto debe convencer al sujeto activo de la obligación tributaria, quien además es él el que admite, decreta, practica y valora las pruebas en el procedimiento tributario.

Otra característica de este procedimiento son las evidentes facultades inquisitivas que tiene la Administración para fiscalizar los tributos, a tal punto que puede decretar de oficio las pruebas que estime necesarias, y puede estimar y presumir hechos, para establecer la obligación tributaria o cuantificarla, como se explicará más adelante. Ahora, sin perjuicio de que la Administración tenga amplias facultades de fiscalización, ello no significa que no deba observar los principios al debido proceso, igualdad, eficacia o justicia, pues los mismos fueron consagrados en la Constitución de 1991 para que fueran aplicados sin excepción en todos los proce- dimientos, con la finalidad de preservar los derechos y garantías de las personas dentro de esos trámites.

Esos mismos postulados le imponen a la Administración la obligación de motivar los actos que modifican la declaración tributaria, a fin de que el contribuyente pueda ejercer debidamente el derecho de defensa y contradicción. Para tal efecto, la motivación debe contraerse a la declaración tributaria y a los hechos planteados desde el inicio de la investigación tributaria en el requerimiento especial o emplazamiento para declarar, según el caso, pues la discusión que estos planteen constituirá el marco de toda la actuación administrativa de la DIAN ${ }^{6}$.

Ahora, precisada la naturaleza y el trámite del procedimiento tributario de aplicación de los tributos, se procede a abarcar el régimen jurídico de la carga de la prueba que rigen en este tipo de procedimientos.

Para Zornoza Pérez (2006, pág. 35-36), en materia tributaria no existe la carga de la prueba en el sentido procesal civil. El autor sustenta su tesis en los siguientes argumentos:

[L]a mayor parte de los códigos tributarios comparados y, entre ellos, el Estatuto Tributario y la LGT recogen reglas -más o menos afortunadas, según los casos- relativas a la distribución de la carga de la prueba, a los medios de prueba y su valoración, al valor

\footnotetext{
${ }^{6} \mathrm{Cfr}$. artículo 711 del Estatuto Tributario, que establece el principio de correspondencia entre la declaración, el requerimiento y la liquidación de revisión. Adicionalmente, debe tenerse en cuenta que con fundamento en los artículos 29 de la Constitución Política y 683 del Estatuto Tributario, la Administración debe respetar el derecho de defensa de los contribuyentes, lo que impone que desde un comienzo se les informe sobre los hechos discutidos y las pruebas que existen en su contra.
} 
de determinados documentos oficiales y de las presunciones; reglas que conviene analizar en sus principales extremos, comenzando por las relativas a la distribución de la carga de la prueba.

En cuanto a las primeras, en la teoría general del proceso, las reglas relativas a la distribución de la carga de la prueba hacen referencia a las instrucciones dadas al juez respecto al contenido de la resolución que debe pronunciar cuando no alcance el convencimiento sobre las circunstancias de hecho afirmadas por las partes. Y, precisamente por ello, se ha podido decir que en los procedimientos tributarios, dado que no se produce el non liquet que sobreviene en el proceso como consecuencia de la falta de prueba, no existe la carga de la prueba en el sentido procesal civil. Ciertamente, en los procedimientos tributarios no existen disposiciones generales que establezcan las consecuencias jurídicas que hayan de producirse cuando, por falta de prueba, subsista la incertidumbre sobre la existencia o inexistencia del presupuesto de hecho de las obligaciones tributarias o sobre alguno de los elementos determinantes de su cuantía; pero ello no se debe a la inexistencia de reglas sobre la carga de la prueba, al menos en su sentido objetivo, sino solo al hecho de que la Administración tiene atribuida la potestad de desplegar una actividad probatoria que supla o complemente la actividad de parte $y$, en concreto, la potestad de estimar los elementos determinantes de la cuantía de la obligación tributaria cuando, constando la realización del hecho imponible, no se encuentre en condiciones de probar dichos elementos debido al comportamiento del obligado tributario.

En principio, se coincide con este autor cuando señala que la Administración cuenta con amplias facultades probatorias para fundamentar su decisión, aun ante la existencia de un hecho incierto, pues la normativa tributaria le permite en ciertos casos establecer y cuantificar la obligación tributaria con fundamento en estimaciones, indicios y presunciones. Pero se disiente, porque en el presente estudio se advierte que hay un caso, en el que ante la existencia de un hecho incierto la ley le impone a la Administración la obligación de decidir en favor del contribuyente, como se contempla en el artículo 745 del Estatuto Tributario, que se explicará más adelante.

Ahora bien, las reglas de la carga de la prueba fueron establecidas en el Estatuto Tributario de forma general, dispersa y poco clara. A continuación, las precisamos en la siguiente forma:

\section{i. Cuando el contribuyente presenta de-} claración tributaria. La primera regla de distribución de la carga de la prueba consiste en que la entidad fiscal debe desvirtuar la presunción $n^{7}$ de veracidad consagrada en el artículo 746 del Estatuto Tributario, según la cual se consideran ciertos los hechos registrados en las declaraciones tributarias. Esta presunción es de carácter legal y, en esa me-

\footnotetext{
${ }^{7}$ La presunción es un indicio determinado por la ley que puede ser legal o de Derecho, conforme se infiere del artículo 66 del Código Civil. La presunción legal admite la prueba en contrario; la presunción de Derecho, no.
} 
dida, admite prueba en contrario del hecho que el legislador señaló como probado. Sin embargo, esa presunción no aplica cuando sobre tales hechos se haya solicitado una comprobación especial o la ley lo exija, caso en el cual la carga de la prueba radica en el contribuyente.

La segunda regla de distribución de la carga de la prueba se concreta en que una vez la Administración controvierta la presunción de veracidad o solicite la comprobación especial, ya sea por iniciativa de la Administración o por exigencia de la ley, le corresponde al contribuyente demostrar los hechos de los cuales se deriva derechos a su favor, teniendo la oportunidad de realizarlo durante la etapa de fiscalización e investigación, en las respuestas a los requerimientos o en los recursos interpuestos contra las actuaciones administrativas $^{8}$.

\section{ii. Cuando el contribuyente no presenta} la declaración tributaria. En primer lugar, la carga de la prueba la tiene la Administración que debe verificar el incumplimiento de la obligación formal, y cuantificarla. Esa regla de juicio se la impone el artículo 715 del Estatuto Tributario, que le exige a la Administración que el emplazamiento para declarar debe proferirlo previa comprobación de la obligación tributaria. Una vez ese acto preparatorio es puesto en conocimiento del obligado tributario, se invierte la carga de la prueba sobre el administrado, correspondiéndole aportar las pruebas necesarias para desvirtuar los supuestos de hecho que para la Administración dan lugar al nacimiento de la obligación tributaria.

\section{iii. En las presunciones contempladas en} materia tributaria. En materia tributaria, el artículo 756 del Estatuto Tributario autoriza a la Administración para adicionar ingresos en el impuesto de renta, aplicando las presunciones que consagra ese código ${ }^{9}$. Como, por ejemplo, las presunciones por omisión del NIT o nombre en la correspondencia, facturas y recibos (artículo 755), por diferencias de inventarios (artículo 757), por control de ventas o ingresos gravados (artículo 758), por omisión de registro de ventas o prestación de servicios (artículo 759) y por omisión del registro de compras (artículo 760). Todas esas presunciones son de carácter legal ${ }^{10}$, pues admiten prueba en contrario, como lo dispone el artículo 761 ibídem. En tal caso, el contribuyente tiene la carga de la prueba, pero además, cuando pretenda desvirtuar los hechos base de la presunción con la contabilidad, deberá acreditar pruebas adicionales.

iv. Cuando existan indicios en contra del contribuyente. En los artículos 754 y 754-1 del Estatuto Tributario se consagran como

\footnotetext{
${ }^{8}$ Cfr. Artículo 744 del Estatuto Tributario.

${ }^{9}$ Autores como Whittingham García (2005, p. 75) señalan que las presunciones “son juicios lógicos del legislador o de los jueces en virtud de los cuales, de la existencia de un hecho reconocido previamente como cierto, se deduce en general o para el caso específico, la existencia de otro hecho distinto, que es preciso demostrar".

${ }^{10} \mathrm{De}$ acuerdo con el artículo 66 del Código Civil, las presunciones pueden ser legales o Derecho. Las primeras admiten prueba en contrario; las segundas, no. En tal sentido, estas últimas -las de Derecho- no pueden ser desvirtuadas, pero como lo precisa la citada autora, ello no impide que el hecho en que se sustenta el supuesto normativo pueda ser controvertido con otros medios de prueba.
} 
indicios ${ }^{11}$ los datos estadísticos y las estadísticas de sectores económicos para efectos de establecer el valor de los ingresos, costos y deducciones, activos patrimoniales e impuestos descontables. Los autores Cermeño, De Bedout, Andrés y Clopatofsky (2016, pp. 316-317) precisan que dada la naturaleza de los indicios, estos no tienen la entidad suficiente para que, por sí solos, se autorice a la Administración a liquidar el tributo. Se considera que, si bien la Administración debe complementar la prueba indiciaria con otras de mayor valor probatorio, le corresponde al contribuyente la carga de desvirtuar tanto los indicios como las demás pruebas en que sustente la actuación administrativa.

\section{v. Cuando se practican inspecciones tri-} butarias o contables. Estas diligencias son un medio de prueba excepcional con el que cuenta la Administración tributaria para decretar, practicar y valorar las pruebas que considere necesarias para determinar la obligación tributaria. Los autores Cermeño, De Bedout, Andrés y Clopatofsky (2016, pp. 128 y ss.) señalan que el objeto de la inspección tributaria consiste en la verificación de la exactitud de la depuración del tributo, así como del cumplimiento correcto y oportuno de las formalidades. Por su parte, la inspección contable recae en forma exclusiva en la documentación contable del contribuyente o de terceros.

Esos autores también precisan que el alcance y fuerza probatoria de la inspección contable está circunscrita a la presunción legal de tener como demostrado y probado que los datos consignados en el acta de esa inspección corresponden a los registrados en la contabilidad del contribuyente. Por consiguiente, la carga de la prueba de desvirtuar dicha presunción legal recae sobre el inspeccionado. En la inspección tributaria, la carga de la prueba también recae sobre el contribuyente, a quien le corresponde demostrar la correcta determinación de la obligación tributaria.

vi. En los casos en que el contribuyente no presente la prueba contable cuando la Administración se lo exija. En principio, la contabilidad constituye prueba a favor del contribuyente, siempre que se lleve en debida forma (artículo 772 E.T.). Para que se entienda llevada en debida forma, la contabilidad debe cumplir las exigencias que de su presentación, conservación y registro establecen el Decreto 2649 de 1993 -reglamentario de la contabilidad en general y de los principios o normas de contabilidad-y el Estatuto Tributario, en particular, los artículos 773 -forma y requisitos de llevar la contabilidad-y 774 -requisitos para que la contabilidad constituya prueba. Es por eso que cuando la autoridad tributaria exija la presentación de la contabilidad y esta no sea aportada por el obligado tributario, el artículo 781 del Estatuto Tributario prescribe que "no podrá ser invocada posteriormente como prueba a su favor y tal hecho se tendrá como indicio en su contra". En tal

\footnotetext{
${ }^{11}$ Whittingham García (2005,p. 71) define a los indicios como la prueba de cualquier hecho conocido, del cual se infiere otro hecho desconocido, para concluir que antes que un medio de prueba es un hecho que aparece probado por cualquiera de los medios probatorios establecidos en la ley, y que se encuentra vinculado al hecho que se pretende probar.
} 
caso, la norma establece una consecuencia jurídica adversa para el contribuyente que no aporte la prueba contable, que consiste en el desconocimiento de los costos, deducciones, descuentos y pasivos. Sin embargo, la norma precisa que tal consecuencia no tendrá lugar cuando el contribuyente los acredite plenamente, siempre que pruebe que la contabilidad no fue presentada por motivos de fuerza mayor o caso fortuito.

Esta norma -781 E.T.- constituye una verdadera regla de la carga de la prueba, al establecer, por un lado, una norma de conducta al contribuyente, consistente en que debe aportar la contabilidad cuando le sea exigida, o demostrar que no puede aportarla por hechos constitutivos de fuerza mayor o caso fortuito, $y$, por el otro, dispone una regla de juicio a la Administración en el sentido de que cuando la prueba contable no sea aportada o no se acrediten las circunstancias especiales señaladas, debe desconocer los costos, deducciones, pasivos y descuentos. En este caso, es clara la consecuencia jurídica adversa que se presenta al contribuyente por no cumplir con la carga de la prueba. Adicionalmente, se coincide con Whittingham (2005, p. 85) cuando señala que, en este caso, la ley tributaria le dio un especial carácter a la prueba indiciaria, en tanto resulta suficiente que se dé el hecho calificado de indicio -no presentación de la contabilidad- para que proceda válidamente el rechazo de los costos, deducciones, descuentos y pasivos.

vii. En los casos en que el contribuyente realice una confesión. Los autores Cermeño, De Bedout, Andrés García y Clopatofsky (2016, p. 311) precisan que confesar un hecho es reconocer como verdadero el hecho de índole suficiente para producir contra el que lo admite consecuencias jurídicas. En materia tributaria, la confesión constituye plena prueba en contra del contribuyente, y se presenta en los siguientes eventos: (i) Los escritos dirigidos por el contribuyente legalmente capaz en los que se informe la existencia de un hecho físicamente posible que perjudique al contribuyente (artículo 747 E.T.). En estos casos, la carga de la prueba la tiene el contribuyente, a quien le corresponde demostrar la prueba de error o fuerza sufridos por este, o el dolo de un tercero, o falsedad material del escrito contentivo de ella; (ii) el artículo 748 del Estatuto Tributario establece una presunción legal-admite prueba en contrario-en contra del contribuyente requerido por escrito o verbalmente, que dé una respuesta evasiva o se contradiga sobre un determinado un hecho. Esta presunción debe ser desvirtuada por el contribuyente demostrando un cambio de dirección o error al informarlo.

Todo lo anterior, debe observar el principio de indivisibilidad de la confesión consagrado en el artículo 749 del Estatuto Tributario, que excluye al contribuyente de probar las expresiones sobre circunstancias inseparables a las afirmaciones de certeza que da sobre un hecho. Adicionalmente, se debe tener en cuenta que el contribuyente que confiesa un hecho en materia tributaria tiene la carga de la prueba de desvirtuarlo, así como de probar las circunstancias que constituyan un hecho distinto al confesado.

viii. La normativa tributaria establece circunstancias especiales que deben ser probadas por el contribuyente. Dentro de 
estas se encuentran los ingresos no constitutivos de renta (artículo 786), los pagos y pasivos negados por los beneficiarios (artículo 787), las circunstancias que lo hagan acreedor de una exención (artículo 788), los hechos que justifican aumento patrimonial (artículo 789), de los activos poseídos a nombre de terceros (artículo 790), las transacciones efectuadas con personas fallecidas (artículo 791). Se trata de casos específicos agrupados en el Capítulo III del Estatuto Tributario, sobre los cuales la ley de forma expresa estableció la carga de probar sobre el contribuyente. De tal manera que si tales hechos no son soportados por este en las oportunidades probatorias dispuestas en el artículo 744 del Estatuto Tributario, no pueden tenerse en cuenta en la determinación de la obligación tributaria.

\section{ix. Cuando profieran requerimientos ordi-} narios. La Administración puede requerir a cualquier contribuyente solicitándole determinada información. En tal caso, el obligado tributario tiene la carga de suministrar y soportar la información solicitada, so pena de incumplir con uno de los deberes de colaboración que impone la normativa tributaria -artículo $686^{[12]}$-, lo que daría lugar no solo a tener por no tener soportado determinado hecho requerido por la DIAN, sino también a la imposición de la sanción por no enviar información dispuesta en el artículo 651 del Estatuto Tributario.

\section{x. Cuando existan dudas por vacíos pro-} batorios. En estos eventos consideramos que sí se contempla una consecuencia jurídica ante la presencia de un hecho incierto. Se trata de la consagrada en el artículo 745 del Estatuto Tributario, en la que se dispone que las dudas provenientes de vacíos probatorios deben resolverse a favor del contribuyente. Sin embargo, esta regla solo opera cuando el contribuyente no se encuentra obligado a probar las circunstancias especiales de que tratan el capítulo III del del título VI que consagra el régimen probatorio, y que se refieren a los ingresos no constitutivos de renta, los pagos y pasivos negados por los beneficiarios, los hechos que los hacen acreedores de una exención o que justifican un aumento patrimonial, los activos poseídos a nombre de terceros, y las transacciones efecutadas con personas fallecidas -artículos 786 a 791 del Estatuto Tributario. De tal manera que, en aquellos eventos en que el contribuyente no deba probar esos hechos y la Administración tenga dudas por vacíos probatorios, la carga de la prueba recae en la entidad fiscal, que deberá hacer lo posible por eliminarlas, y en caso de que ello no ocurra, la ley establece como consecuencia jurídica que la DIAN debe darle la razón al contribuyente.

xi. No existencia de carga de la prueba. Considero la existencia de una regla de no existencia de la carga de la prueba que se presenta respecto de aquellos he-

\footnotetext{
${ }^{12}$ Artículo 686. Deber de atender requerimientos. Sin perjuicio del cumplimiento de las demás obligaciones tributarias, los contribuyentes de los impuestos administrados por la Dirección General de Impuestos Nacionales -U.A.E. DIAN-, así como los no contribuyentes de los mismos, deberán atender los requerimientos de informaciones y pruebas relacionadas con investigaciones que realice la Administración de Impuestos, cuando a juicio de esta, sean necesarios para verificar la situación impositiva de unos y otros, o de terceros relacionados con ellos.
} 
chos que los contribuyentes aceptan en los recursos. En estos casos, el artículo 723 ibídem dispone que esos hechos no pueden ser objetados por el recurrente. Es decir, el contribuyente no puede controvertirlos, solo la Administración.

xii. Hechos constitutivos y exceptivos. Finalmente, autores como Hensel (2005, p. 335), Zornoza (2006, p. 37) y Rodríguez-Bejeiro (2001, p. 12) sostienen que la autoridad tributaria debe probar todas las circunstancias de hecho y Derecho determinantes de la obligación tributaria; por el contrario, el obligado tributario tiene que demostrar los hechos que excluyen o minoran la obligación.

De todo lo expuesto, puede concluirse que la Administración cuenta con amplias facultades inquisitivas en el procedimiento tributario, que le generan una obligación general de recaudar cuantas pruebas sean relevantes para el conocimiento de la verdad. Ello, por cuanto en el ordenamiento tributario se establecen muchos deberes de colaboración a cargo de los contribuyentes, y amplias facultades de fiscalización para la DIAN, que le pemiten a esta última disponer de un alto volumen de datos para determinar la obligación tributaria. Pero, ello no puede significar que la carga de la prueba recaiga siempre sobre la Administración, pues, como se observó en líneas anteriores, en la determinación de la obligación tributaria el contribuyente tiene el deber de allegar las pruebas en las oportunidades procesales que dispone la ley, y en particular, probrar los hechos que pueden derivarle derechos a su favor, como es el caso de los costos y deducciones, que pasan a analizarse.

\section{Normas del Estatuto Tributario sobre la carga de la prueba en materia de costos y deducciones en el impuesto de renta}

Mediante la Ley 1819 de 2016, se adoptó una reforma tributaria estructural, que fijó nuevos parámetros para el reconocimiento de los costos y gastos en el impuesto de renta. El artículo 22 de la Ley 1819 de 2016, que adicionó el artículo 21-1 del Estatuto Tributario, prevé que para la liquidación del impuesto de renta de los contribuyentes obligados a llevar contabilidad, debe tomarse como valor de los costos y deducciones el señalado en las normas NIIF, siempre que así lo disponga la ley o cuando se presenten vacíos normativos, con excepción de los casos en que la normas tributarias prevean otro tratamiento. Es por eso que autores como Piza Rodríguez J. (2016, p. 71) precisan que el reconocimiento de los costos y deducciones quedó condicionado a que se "satisfagan las definiciones y criterios de reconocimiento previstos para los respectivos elementos (ingresos, costos, gastos, activos pasivos) en las NIIF", lo que vislumbra la existencia de una interacción entre las normas contables y las fiscales. En relación con los contribuyentes no obligados a llevar contabilidad, la reforma tributaria no modificó su forma de reconocimiento, pues se siguen realizando al momento del "pago efectivo o en especie, o cuando su exigibilidad termine por cualquier otro modo que equivalga legalmente a un pago". Pero en todo caso, si estos deciden llevar contabilidad deben sujetarse a las disposiciones tributarias de los obligados y a las normas NIIF.

En materia probatoria, las normas fiscales sujetan la procedencia de los costos y deducciones a que se encuentren soportados en 
facturas o en documentos equivalentes ${ }^{13}$ que cumplan con los requisitos señalados en el artículo 771-2 del Estatuto Tributario. Pero si no existe la obligación de expedir factura o documento equivalente, el documento que pruebe la respectiva transacción que da lugar a los costos o deducciones deberá cumplir los requisitos mínimos que establezca el Gobierno Nacional ${ }^{14}$.

Ahora bien, la normativa tributaria establece normas especiales en materia de costos y deducciones en las que se verifica la carga de la prueba y la aplicación de los sistemas inquisitivo y dispositivo de la actividad probatoria.

i. Costos estimados y presuntos. El artículo 82 del Estatuto Tributario le otorga facultades a la Administración para estimar o presumir los costos cuando no exista certidumbre sobre la existencia de esa erogación. La incertidumbre sobre los costos debe generarse por la existencia de indicios de que el costo no es real, o no se conozca el costo de los activos enajenados ni sea posible su determinación mediante pruebas directas, tales como la declaración de renta del contribuyente o de terceros, la contabilidad.

Esta norma supone que la Administración ejerció sus amplias facultades de fiscaliza- ción y que el contribuyente ejerció su actividad probatoria aportando los soportes de los costos. Pero, las pruebas recaudadas no le permiten a la Administración establecer de forma directa la realidad y el valor del costo declarado por el contribuyente. $\mathrm{Al}$ no encontrarse esas circunstancias debidamente probadas por el contribuyente, se genera para este el desconocimiento de los costos declarados y, en su lugar, se estimará esa erogación con los realizados por un comerciante que realiza su misma actividad y con fundamento en estadísticas oficiales. En ese sentido, se observa que la estimación es una solución que da la ley tributaria a la Administración para resolver el non liquet que se presenta en relación con los costos y en esta se vislumbran las preponderantes facultades inquisitivas que tiene esa autoridad en el procedimiento tributario.

\section{ii. Deducción por pagos al exterior. Una} norma especial en materia de la carga de la prueba es la contemplada en el artículo 123 del Estatuto Tributario, modificado por el artículo 72 de la Ley 1819 de 2016, cuando la deducción por expensas al exterior se origina en pagos que realizó el contribuyente a una persona natural extranjera o una sucesión de extranjeros sin residencia en el país, o una sociedad u otra entidad extranjera sin domicilio en Colombia. Esta disposición exige al

\footnotetext{
${ }^{13}$ En virtud de lo dispuesto en los artículos 615 del Estatuto Tributario y 1.6.1.4.1. del Decreto 1625 de 2016 -DUR-, todas las personas o entidades que tengan la calidad de comerciantes, ejerzan profesiones liberales o presten servicios inherentes a estas, o enajenen bienes producto de la actividad agrícola o ganadera, deberán expedir factura o documento equivalente.

Así mismo, el artículo 618 del Estatuto Tributario les impone la obligación a los contribuyentes adquirientes de bienes corporales muebles o de servicios que en dichas transacciones exijan facturas o documentos equivalentes, y les establece la responsabilidad de exhibirlo cuando la Administración así lo exija.

${ }^{14}$ El artículo 1.6.1.4.44. del Decreto 1625 de 2016 -DUR-, establece los requisitos para la procedencia de los costos y deducciones en las operaciones realizadas con no obligados a facturar.
} 
contribuyente que debe acreditar a la Administración la consignación del impuesto retenido en la fuente a título de renta, so pena del desconocimiento de la deducción. Lo mismo sucede con los gastos generados por concepto de contratos de importación de tecnología, patentes y marcas, en tanto los supedita a que tales convenios se registren ante el organismo oficial competente dentro de los 6 meses siguientes a la suscripción del mismo ${ }^{15}$.

De tal manera que la carga de la prueba de esta erogación recae sobre el obligado tributario y su incumplimiento genera una consecuencia jurídica adversa para este, como lo es el rechazo de la deducción. Súmese a ello que la Ley 1819 de 2016 adicionó el artículo 771-6 al Estatuto Tributario, que le otorga una facultad especial a la DIAN para rechazar costos y gastos en el exterior, cuando verifique que a) el beneficiario del $50 \%$ o más de dichos pagos es directa o indirectamente el mismo contribuyente y b) el pago se efectúa en una jurisdicción no cooperante o de menor o nula imposición o a entidades sometidas a un régimen tributario preferencial, o no se allegue certificado de residencia fiscal del beneficiario del pago. Bajo esos supuestos, la única posibilidad que contempla la norma para evitar el rechazo de los costos es imponer sobre el contribuyente la carga de demostrar "que la estructura jurídica obedece a un propósito principal de negocios, diferente al ahorro tributario, lo cual podrá hacerse a través de la aplicación del régimen de transferencia". Por lo que se considera que el legislador parte de presumir que no son reales los costos y gastos al exterior que encuadren en la hipótesis normativa, y como consecuencia de ello establece una comprobación especial sobre los mismos, a fin de evitar la evasión tributaria.

\section{iii. Deducción por deudas manifiestamente} perdidas o sin valor. Por su parte, el artículo 146 del Estatuto Tributario establece sobre el contribuyente la carga de probar la deducción por deudas manifiestamente perdidas o sin valor. El obligado tributario que lleve contabilidad por el sistema de causación debe demostrar la realidad de la deuda, justificar su descargo y soportar que se ha originado en operaciones productoras de renta. Quienes no llevan la contabilidad indicada deben conservar el documento concerniente a la deuda con constancia de su anulación. De no aportarse la prueba solicitada en la norma por parte del contribuyente, se genera el desconocimiento de la deducción solicitada.

\section{iv. Pagos negados por los beneficiarios.} El artículo 787 del Estatuto Tributario contempla como una de las circunstancias especiales que deben ser demostradas por el contribuyente, los pagos y pasivos negados por los beneficiarios. La norma parte del hecho de que el contribuyente cumple con todos los requisitos legales para la aceptación de costos y deducciones, pero el tercero beneficiario niega el pago. En tal sentido,

${ }^{15}$ Antes de la Ley 1819 de 2016, el legislador no supeditaba la procedencia de la deducción a que el registro de los convenios se hiciera dentro de un plazo determinado. No obstante, la DIAN estableció un término para el registro de esos contratos mediante la Resolución No. 000062 del 24 de febrero de 2014, lo que generó una discusión legal sobre el establecimiento del requisito de procedencia de la deducción en un acto reglamentario. Pero esa discusión no se presenta actualmente, toda vez que ese requisito fue elevado a rango legal con la reforma tributaria de la Ley 1819 de 2016. 
la ley le impone al contribuyente la carga de informar a la DIAN las circunstancias de tiempo, modo y lugar referentes a esa situación. Caso en el cual la carga de la prueba se traslada a la Administración, que deberá realizar la investigación respectiva.

Se deriva de todo lo expuesto, que la regla general de la carga probatoria en el procedimiento tributario consiste en que a la Administración le corresponde desvirtuar la presunción de veracidad de las declaraciones mediante sus facultades de comprobación. Por su parte, al contribuyente le corresponde la prueba de los costos y deducciones declarados, toda vez que la ley dispuso sobre este la responsabilidad de demostrarlos con los documentos exigidos en la ley, en los eventos en que la Administración requiera los soportes de esas erogaciones.

Pero, lo cierto es que en la normativa tributaria no existe una referencia específica sobre las consecuencias que se generan para los sujetos de la obligación tributaria y para la Administración ante la persistencia de un hecho incierto en el trámite del procedimiento tributario, salvo la contemplada en el artículo 745 del E.T.

Es precisamente con fundamento en esa norma que en este escrito se concluye que en el procedimiento administrativo tributario sí existe la carga de la prueba, esto es, una regla que impone una consecuencia negativa a una parte por la falta de aportación de prueba. En este caso, la parte que soporta ese resultado adverso es la DIAN ante la persistencia de vacíos probatorios, a excepción de que los mismos recaigan sobre circunstancias especiales que deben probar los contribuyentes, caso en el cual la consecuencia negativa recae sobre el obligado tributario. La interpretación de esta regla será presentada en forma amplia en los criterios de la carga de la prueba que se concretarán en este estudio.

A continuación se analizarán las reglas de la carga de la prueba en el marco del proceso judicial, en las que se vislumbran los problemas que se presentan en la distribución de esa responsabilidad procesal en la resolución de los conflictos jurídicos que se surgen entre los particulares y entre el Estado, o entre las entidades del mismo.

\section{Las normas jurídicas que regulan la carga de la prueba en el proceso contencioso administrativo}

Las controversias que en materia tributaria se presentan entre la Administración y los contribuyentes se resuelven ante la jurisdicción contenciosa administrativa con el medio de control de nulidad y restablecimiento del derecho regulado en la Ley 1437 de 2011 "Código de Procedimiento Administrativo y de lo Contencioso Administrativo ${ }^{16}$ ". De tal manera que el contribuyente que se crea lesionado en su derecho por un acto administrativo particular expedido por la DIAN en el procedimiento de aplicación de los tributos, podrá solicitar ante la jurisdicción -autoridad judicial ajena a la relación jurídica tributaria ${ }^{17}-$,

\footnotetext{
${ }^{16}$ Esa legislación derogó el Decreto 01 de 1984 "Código Contencioso Administrativo".

${ }^{17}$ El artículo 228 de la Constitución Política señala que las decisiones de la Administración de justicia son independientes y su funcionamiento será autónomo.
} 
que declare la nulidad de tal acto y le restablezca el derecho ${ }^{18}$.

En el proceso contencioso administrativo ${ }^{19}$, tanto las partes como el juez tienen una posición activa en la actividad probatoria. Por un lado, desde la interposición de la demanda y su contestación, las partes tienen la obligación de allegar todas las pruebas que tengan en su poder. Además, tienen otras oportunidades probatorias: en primera instancia, en la reforma de la demanda y su respuesta; la demanda de reconvención y su contestación; las excepciones y la oposición a las mismas, y los incidentes y su respuesta. En segunda instancia, podrá pedirse el decreto de prueba cuando sea de común acuerdo, o las decretadas en primera instancia se dejaron de practicar por alguna circunstancia no atribuible a la parte que la pidió, o verse sobre hechos nuevos, o que no fueron solicitadas por fuerza mayor o caso fortuito, o traten de desvirtuar estos últimos dos eventos.

Por el otro, el juez tiene amplias facultades para decretar pruebas de oficio en cualquiera de las instancias cuando las considere necesarias para el esclarecimiento de la verdad, o proferir autos de mejor proveer antes de dictar sentencia. En efecto, en el artículo 213 del CPACA se dispone que en cualquiera de las instancias el juez puede decretar de oficio las pruebas que considere necesarias para el esclarecimiento de la verdad. Pero precisa que estas deben decretarse y practicarse conjuntamente con las pedidas por las partes.

Para Betancur Jaramillo (2013, p. 444), esa exigencia coarta la facultad oficiosa del juzgador, pues señala que si las partes no solicitan pruebas, no podría ejercer dicha potestad. Sin embargo, se considera que la norma, en virtud del principio de economía procesal, establece que tanto las pruebas de oficio como las solicitadas por las partes se decreten y se practiquen conjuntamente, lo que no quiere decir que el juez no pueda decretar pruebas de oficio cuando las partes no solicitan pruebas, pues no puede perderse de vista que el artículo 213 del CPACA dispuso que esa facultad podía ser ejercida por el juez en cualquiera de las instancias del proceso, esto es, aun aquellas que no son propias de la etapa probatoria.

Adicionalmente, el artículo 213 ibídem faculta al juez a proferir "autos de mejor proveer", esto es, aquellos emitidos una vez

\footnotetext{
${ }^{18}$ Artículo 138 CPACA. Igualmente podrá pretenderse la nulidad del acto administrativo general y pedirse el restablecimiento del derecho directamente violado por este al particular demandante o la reparación del daño causado a dicho particular por el mismo.

${ }^{19}$ El proceso inicia con la presentación de la demanda y prosigue con la celebración de una audiencia inicial que tiene por objeto el saneamiento del proceso para evitar sentencias inhibitorias, decidir las excepciones previas - pretenden el saneamiento del proceso, por causa de vicios o defectos en el mismo-, fijar el litigio, esto es, los hechos discutidos, decretar medidas cautelares, y decretar pruebas. Cuando se trate de asuntos de puro derecho o no fuere necesario practicar pruebas, el juez prescindirá de la segunda etapa y procederá a dictar la sentencia dentro de la audiencia inicial, dando previamente a las partes la posibilidad de presentar alegatos de conclusión. En los demás casos, se procede a celebrar la audiencia de prueba, en la que el juez recaudará todas las pruebas solicitadas y decretadas. Las pruebas se practicarán en la misma audiencia en presencia de las partes. Luego de recopilado el material probatorio en el proceso, el juez puede celebrar una audiencia de alegaciones y de juzgamiento, en la que puede proferir sentencia, o emitirla por escrito en fecha posterior (artículos 180 y 181 CPACA).
} 
oídas las alegaciones de las partes y antes de proferir sentencia, con la finalidad de esclarecer puntos oscuros o difusos de la contienda. Coincidimos con Betancur Jaramillo (2013, p. 444) cuando señala que la justificación de los autos de mejor proveer es el hecho de que la valoración de las pruebas recaudadas no dan la suficiente certeza que se requiere para tomar la decisión. Este autor precisa que lo dudoso se refiere a la falta de convicción plena sobre la existencia de los hechos. En cambio, lo difuso se refiere más a la falta de precisión de los hechos determinantes del proceso.

No obstante lo dicho, debe advertirse que en el procedimiento contencioso administrativo no existe una regulación de la carga de la prueba, como sí la tiene el Código General del Proceso-CGP-20 ${ }^{20}$, en el artículo 167. Pero, dada la remisión expresa en materia probatoria que ordena el CPACA a las normas de procedimiento civil $^{21}$, en los procesos contenciosos administrativos que versen en materia tributaria, resultan aplicables las reglas de la carga de la prueba prevista en el citado artículo 167.

Así también lo entiende Benavides (2016, p.541), pero además precisa que la aplicación de esa norma debería realizarse por el juez en la audiencia inicial al momento de decretar las pruebas pedidas por las partes y las de oficio, para que no se presenten vulneraciones a los derechos de igualdad, debido proceso y defensa.
El artículo 167 del CGP contempla como regla general el principio dispositivo de las pruebas, pero establece excepciones: las facultades oficiosas del juez y la carga dinámica de la prueba, la última de las cuales impone la carga de la prueba a la parte que se encuentre en una posición favorable de aportarla.

La primera regla "incumbe a las partes probar el supuesto de hecho de las normas que consagran el efecto jurídico que ellas persiguen", reitera el postulado que establecía el artículo 177 del Código de Procedimiento Civil.

La segunda regla, "según las particularidades del caso, el juez podrá, de oficio o a petición de parte, distribuir la carga al decretar las pruebas, durante su práctica o en cualquier momento del proceso antes de fallar", fue adicionada con el nuevo código, y plasma el postulado de la carga dinámica de la prueba. Para ello, estableció una regla de juicio, que se concreta en que la carga de probar el hecho debe exigirse a la parte que se encuentre en una situación más favorable para aportar la prueba, en virtud (i) de su cercanía con el material probatorio, (ii) por tener en su poder el objeto de la prueba, (iii) por circunstancias técnicas especiales, (iv) por haber intervenido directamente en los hechos que dieron lugar al litigio, (v) por estado de indefensión o de incapacidad que se encuentre la contraparte o (vi) por otras circunstancias similares.

\footnotetext{
${ }^{20}$ Normativa con la que el legislador derogó el Código de Procedimiento Civil -Decreto 1400 de 1970-, con la finalidad de establecer un procedimiento acorde con las nuevas orientaciones de la Constitución Política de 1991, en particular con el nuevo rol del juez en el Estado Social de Derecho en materia probatoria.

${ }^{21}$ Artículo 211 del CPACA.
} 
Acerca de la tercera regla, "los hechos notorios y las afirmaciones o negaciones indefinidas no requieren prueba", López Blanco (2008, p. 58) explica que el hecho notorio es aquel que se supone conocido por la generalidad de los asociados cualquiera que sea su grado de cultura o conocimiento dentro de un territorio específico y en determinada época ${ }^{22}$. El motivo por el cual estos hechos no requieren prueba no es la imposibilidad de probarlos sino, precisamente, su conocimiento generalizado. En lo relacionado con las afirmaciones y negaciones indefinidas, el Consejo de Estado (2014, Exp. 30179) ha señalado que son "aquellas que ni indirecta o implícitamente conllevan ninguna afirmación o negación opuesta: que no sólo son indeterminables en el tiempo y en el espacio, sino que, en la práctica, no son susceptibles de probar por medio alguno".

Pues bien, la ponderación que el Código General del Proceso realiza de los deberes de las partes y del juez en materia probatoria fue objeto de estudio por parte de la Corte Constitucional (C-086 de 2016) con ocasión de la demanda de inconstitucionalidad interpuesta contra el artículo 167 del C.G.P., en particular en lo referente a la facultad del juez para distribuir la carga de la prueba ${ }^{23}$, pues para los demandantes la norma no debió contemplarlo como una discresionalidad del juez sino como una obligación.
La alta corporación declaró la exequibilidad de la norma, por cuanto la consagración de la carga dinámica de la prueba como una postetad del juez está encaminada a procurar un prudente equilibrio entre la función del administrador de justicia en el Estado Social de Derecho y el cumplimiento de las cargas procesales impuestas a las partes. Consideró que no estaría acorde con la Constitución establecer la carga dinámica de la prueba como una obligación para el juez, porque ello desconocería las cargas procesales de las partes. No obstante lo anterior, precisó que en algunos casos el decreto oficioso de pruebas o la distribución de la carga de la prueba deja de ser una postestad del juez y se erige como un "verdadero deber funcional". Pero, tal circunstancia debe analizarse de acuerdo con las particularidades de cada caso, sin modificar las reglas generales de distribución de la carga de la prueba. Decisión que pone en evidencia que en el procedimiento civil existen serias dificultades en la ponderación de las cargas procesales de las partes con las facultades de decretar pruebas de oficio por parte del juez.

En definitiva y, de acuerdo con lo estudiado hasta este punto, puede concluirse que el juez cuenta con varias herramientas para resolver un conflicto sobre un hecho incierto: (i) por regla general, debe imponer la carga de la prueba a la parte que alega los hechos, y (ii) por excepción, debe aplicar la carga dinámica de la prueba a la parte que le resulte

\footnotetext{
${ }^{22} \mathrm{El}$ autor precisa que la notoriedad puede ser mundial, continental, regional o puramente municipal y está referida a un determinado lapso, de modo que lo que en un determinado proceso podrá erigirse como notorio, en otro no necesariamente tiene esa connotación.

${ }^{23}$ En la demanda se solicitó la declaratoria de inexequibilidad del aparte que se resalta contenido en el artículo 167 del C.G.P.: "No obstante, según las particularidades del caso, el juez PODRÁ de oficio o a petición de parte, distribuir la carga al decretar las pruebas. [...]".
} 
mas favorable aportarla, o decretar pruebas de oficio cuando tenga alguna duda. Todo, porque el juez siempre debe propender por la busqueda de la verdad, y si después de la utilización de dichas herramientas procesales, persiste el hecho incierto, debe establecer qué parte asume la consecuencia negativa por la falta de la prueba.

En tal sentido, como lo sostiene Palacio (2004, pp. 5- 6 y 18 ss.), "en términos generales corresponde la carga de la prueba en principio al demandante, quien debe probar los hechos en que fundamentó su pretensión, así mismo, atañe al demandado demostrar los sucesos en que basa su defensa, pues como dice Rosenberg, el demandado debe probar los supuestos de la norma gracias a la cual trata de conseguir el rechazo de la demanda. Si quien tenía la obligación de probar un hecho no lo hace, la consecuencia jurídica será que el juez profiera un fallo adverso, ratificando la presunción de legalidad que ampara los actos administrativos y negando las pretensiones. El juez no podrá, por ausencia de pruebas, dictar fallo inhibitorio y mucho menos absterner a fallar".

Pero, como lo reconoce el citado autor, a pesar de la carga probatoria que deben soportar las partes del proceso, es el juez el que debe llegar a la convicción sobre la verdad de los hechos. Es por eso que se le otorgan facultades para que contribuya con el debate probatorio decretando pruebas de oficio. Sin embargo, esta debe ejercerse sin desconocer las garantías constitucionales de las partes, entre estas, el derecho a la igualdad y al debido proceso.

Entonces, de acuerdo con las normas estudiadas, la decisión del juez para establecer la consecuencia jurídica negativa de un hecho incierto debe partir de la siguiente regla de juicio: qué parte no probó su afirmación, o estaba en posición mas favorable para probarla, o no aportó la prueba de la afirmación a pesar de haber sido requerida oficiosamente por el juez. Pero para entender cuando una parte se encuentra en una mejor posición de probar, el juez debe remitirse a los ejemplos contemplados en el artículo 167 del Código General del Proceso -CGP-, los cuales no son taxativos pero sí precisan el criterio que debe tener al momento de aplicar la carga dinámica de la prueba por excepción.

Por consiguiente, podemos afirmar que en el proceso contencioso administrativo tributario sí existen reglas de la carga de la prueba y las consecuencias jurídicas adversas que se generan por su incumplimiento, la pérdida del proceso.

El anterior análisis permite concluir que la carga de la prueba constituye una (i) responsabilidad para las partes de todo proceso o procedimiento, en tanto les informa qué hecho les corresponde probar, y (ii) una regla de juicio para el juez, que le permite decidir ante la persistencia de un hecho incierto, estableciendo sobre una de las partes las consecuencias adversas por la falta de prueba.

Con la expedición de la Constitución de 1991, la tendencia de la carga de la prueba radica no solo en establecer sobre las partes, sino también sobre el juez cierta responsabilidad en la aportación de pruebas. Así, las normas constitucionales fijaron como principios que la administración de justicia debe propender por la búsqueda de la verdad real, y que las partes deben actuar con diligencia y 
asumir las cargas procesales, entre las cuales se encuentra la carga de la prueba.

Todos esos principios fueron recogidos en los nuevos códigos de procedimiento, como el CGP, en el sentido de establecer como regla general la carga de las pruebas sobre las partes, y de forma excepcional, las facultades oficiosas del juez y la aplicación de la carga dinámica de la prueba. Estas últimas con la finalidad de encontrar la verdad real de los hechos y de propender por la aplicación de los principios de igualdad, equidad y lealtad procesal.

Esos postulados igualmente son aplicados en el procedimiento contencioso administrativo, pues si bien fue expedido un nuevo estatuto procesal, ese ordenamiento sigue dependiendo de la regulación que en materia probatoria se ha expedido para el procedimiento civil.

Sin embargo, la carga de la prueba, así entendida, no se aplica en los procedimientos tributarios, en tanto la Administración cuenta con amplias facultades inquisitivas en materia probatoria. Esta entidad actúa como juez y parte en el decreto y valoración de las pruebas, y toma la decisión final en el procedimiento; ello, sin mencionar que, en ciertos casos, puede establecer y cuantificar la obligación tributaria mediante estimaciones, indicios y presunciones.

Pero como se estudió, existe una regla de carga de la prueba específica dentro del procedimiento tributario establecida en el artículo 745 del Estatuto Tributario, en el que, ante la existencia de un hecho incierto, la ley le impone a la Administración la obligación de decidir en favor del contribuyente, en los casos que no se requiera una comprobación especial del mismo hecho.

En materia de costos y deducciones, persisten las facultades inquisitivas de la Administración, pero la normativa tributaria establece en el contribuyente la prueba de los mismos. Sin embargo, no es clara la referencia en cuanto a las consecuencias adversas que se presentan para la Administración o el contribuyente en cuanto a la verificación o aportación de las pruebas por dichos conceptos.

Todo, para señalar que en el procedimiento tributario no existe la carga de la prueba en el sentido civil, a excepción del caso contemplado en el artículo 745 del Estatuto Tributario, toda vez que no es clara la normativa tributaria en establecer las consecuencias que se generan a los sujetos ante la persistencia de un hecho incierto.

Llegada a esa conclusión, se procede a analizar la interpretación que ha realizado el Consejo de Estado sobre las normas procedimientales anteriormente analizadas, que permite observar la aplicación práctica de la carga de la prueba de los costos y deducciones en los procesos judiciales.

\section{Jurisprudencia del Consejo de Estado en materia de la carga de la prueba de los costos y deducciones}

En el capítulo anterior se realizó un análisis de la carga de la prueba con fundamento en la doctrina y las disposiciones jurídicas que tienen alcance en materia tributaria. Lo que permitió concluir que existe el criterio general de que la carga de la prueba recae sobre las partes respecto a sus afirmaciones 
y, excepcionalmente, el juez puede dar aplicación a sus facultades oficiosas o a la carga dinámica de la prueba.

Pero el análisis de la carga de la prueba en el contorno tributario no puede limitarse a lo dicho por los autores y al ámbito de las normas jurídicas que la regulan, sino que también debe tenerse en consideración la jurisprudencia que ha emitido el Consejo de Estado en la materia, pues no puede perderse de vista que el juez es el que sitúa la dimensión jurídica del problema probatorio en cada caso en concreto.

Es por esas razones que las sentencias que contienen las interpretaciones y criterios del Consejo de Estado en materia de la carga de la prueba, aun cuando no constituyan una sentencia unificada y, por ende, un precedente jurisprudencial obligatorio para las autoridades, no puede desconocerse que sirven como juicio orientador para esa corporación y los demás despachos judiciales, en la resolución de aquellos procesos en que no sea posible esclarecer los hechos discutidos.

A partir de lo anterior, la metodología para seleccionar las sentencias más relevantes para este estudio consistió en verificar las diversas situaciones fácticas y probatorias del procedimiento administrativo tributario y el proceso judicial analizadas en el año 2009 a 2017, en las que el fallador dio aplicación a la carga de la prueba, esto es, tomó la decisión judicial a pesar de que no existían pruebas de la procedencia de los costos y deducciones. Una vez clasificadas las sentencias, se realizó un análisis de las mismas, para efectos de identificar el problema probatorio tratado por el Consejo de Estado, la regla de la carga de la prueba aplicada y la consecuencia jurídica de la misma, todo para plantear si existe o no un criterio unificado sobre la carga de la prueba y, si existe cuáles son sus contornos.

\section{A. Jurisprudencia del Consejo de Estado sobre la carga de la prueba en vía administrativa}

Del análisis probatorio que realizó el Consejo de Estado en el marco de la vía administrativa se extraen las siguientes sentencias en las que se aprecia el esfuerzo de la corporación para establecer un criterio de la carga de la prueba, así como la inversión de la misma, dependiendo de la situación probatoria que se presente en cada caso en concreto.

\section{Cuando el contribuyente presenta la declaración}

El alcance de la presunción de veracidad de las declaraciones y la facultad de comprobación de la Administración fue precisado por el Consejo de Estado, Sección Cuarta, en sentencia del 15 de abril de 2010, Exp. 16571. En esa providencia, aplicó el sistema dispositivo que impone a las partes probar sus respectivas afirmaciones, al comprobar que la demandante soportó la deducción, pero la Administración no sustentó el rechazo de esa minoración tributaria. Pero, además, precisó que la comprobación especial de la DIAN debe cumplir unas exigencias mínimas -respaldo probatorio-, que constituye una garantía que resguarda la presunción legal dispuesta sobre las declaraciones tributarias. Siendo que una simple solicitud de la DIAN, sin ningún soporte probatorio, no pueda dar lugar a desvirtuar los datos declarados y, en tal sentido, a trasladar la carga de la prueba al contribuyente, carga que, como se dijo, 
inicialmente radica en la Administración en los casos que el contribuyente presenta la declaración tributaria.

Pero el Consejo de Estado, Sección Cuarta, en sentencia del 10 de marzo de 2011, Exp. 17075, cambió la aplicación del sistema dispositivo, para dar aplicación a la carga dinámica de la prueba, modificando parcialmente el criterio expuesto, en el sentido de que la prueba de los costos y deducciones debe ser aportada por quien tenga mayor facilidad, aunque no sea para demostrar su afirmación. Para ello, expuso el alcance de la carga dinámica de la prueba en la vía administrativa en el sentido de que "en materia tributaria opera, de manera relativa, la carga dinámica de la prueba, en el entendido de que es el contribuyente el que se encuentra en una posición privilegiada para probar el hecho económico declarado".

En esta sentencia, la Sala varió su posición inicial relativa a que a cada parte le corresponde probar su afirmación, para señalar que la carga de la prueba corresponde a la parte que tenga mayor facilidad de hacerse del material probatorio. Sin embargo, en todo caso, para la Sección, el contribuyente es el que se encuentra en una posición privilegiada para probar los datos declarados, lo que a la final se confunde con la aplicación del sistema dispositivo, en tanto aplica la carga dinámica en el contribuyente respecto de los hechos afirmados o declarados por él mismo.

Luego, el Consejo de Estado, Sección Cuarta, en sentencia del 23 de junio de 2011, Exp. 17369, definió los lineamientos de las posiciones de la Sala en torno a la aplicación del sistema dispositivo y de la carga dinámica de la prueba. En efecto, en esa providencia, la ratio decidendi se concretó en que si bien las autoridades tributarias están facultadas para adelantar labores de fiscalización e investigación con el fin de asegurar el efectivo cumplimiento de las normas sustanciales, ello no significa que la carga probatoria que corresponde a los contribuyentes pueda ser sustituida por la que pueda tener la Administración, sin que ello desconozca que en el procedimiento administrativo existe "una dinámica probatoria y de permanente contradicción", que se ve reflejada en cada uno de los actos del contribuyente y de la Administración, y en la que puede darse aplicación a la carga dinámica de la prueba. En tal sentido, la Sala permite una aplicación mixta del sistema dispositivo y la carga dinámica de la prueba, pues parte de que la carga corresponde a la parte que realiza la afirmación, pero si la otra está en mejor posición de aportar una prueba, debe allegarla.

Posteriormente, el Consejo de Estado, Sección Cuarta, en sentencia del 3 de mayo de 2012, Exp. 18135, reiteró que en materia tributaria la carga de la prueba se rige por el sistema dispositivo y, además, que la correspondiente a la DIAN puede cumplirse con la sola solicitud de comprobación de los requisitos de ley, para trasladar la carga al contribuyente. Con lo que morigeró su posición inicial que condicionaba la comprobación especial a la existencia de un respaldo probatorio.

Finalmente, el Consejo de Estado, Sección Cuarta, en sentencia del 20 de enero de 2017, Exp. 20551, continúa con la postura que plantea que para desvirtuar la presunción de veracidad de la declaración tributaria la Administración puede constatar los datos 
declarados mediante el recaudo de pruebas o solicitar al contribuyente la comprobación de los requisitos exigidos para la procedencia de los costos y las deducciones.

De todas esas sentencias puede concluirse que el criterio aplicado por el Consejo de Estado en los casos de presentación de la declaración tributaria consiste en determinar inicialmente la carga de la prueba sobre la Administración en virtud de la presunción de veracidad en que se amparan las declaraciones. Pero una vez la Administración satisface su carga de la prueba, la misma se traslada al contribuyente, al que le corresponde desvirtuar la valoración probatoria en que se fundamentan los actos de determinación y discusión tributaria.

En todo ello se vislumbra que la jurisprudencia ha sido uniforme en la aplicación general del sistema dispositivo y, excepcional, de la carga dinámica de la prueba, pues la Sala exige a las partes la aportación de las pruebas en que sustenta su afirmación, pero, principalmente, impone sobre el contribuyente la aportación de las documentos soportes idóneos previstos en la legislación tributaria para la demostración de los costos, como son las facturas, documentos equivalente o los exigidos por el Gobierno Nacional, dependiendo de cada caso.

\section{Cuando el contribuyente no presenta declaración}

El Consejo de Estado, Sección Cuarta, en las sentencias del 2 de agosto de 2012, del 27 de marzo de 2014 y del 4 de febrero de 2016, Exp. 18696, 18634 y 20979 , respectivamente, establece que la carga de prueba recae sobre la DIAN para comprobar la existencia de la obligación tributaria, el obligado, la base gravable y la cuantía, así como de la no presentación de la declaración, con fundamento en un acervo probatorio. Pero, además, le exige que esa comprobación conste en un acto denominado emplazamiento para declarar, para que se dé inicio a la investigación tributaria. Una vez satisfecha la carga de la prueba de la Administración, esta se traslada al contribuyente, que debe desvirtuar la existencia de la obligación o de la falta de presentación de la declaración, dependiendo de cada caso. Si bien en estos casos el contribuyente no presenta declaración tributaria que goce presunción de veracidad, la Sala le da igual tratamiento a la respuestas que presente, a menos que se trate de las circunstancias especiales que deben ser probadas por los contribuyentes.

Este criterio muestra que en esos casos, la Sala continúa con la aplicación del sistema dispositivo en tanto deja a las partes la aportación de las pruebas en que sustenta cada una de sus afirmaciones.

\section{Cuando el contribuyente está obligado a llevar contabilidad}

El Consejo de Estado, Sección Cuarta, en las sentencias del 4 de marzo de 2010,23 de enero de 2014, 21 de agosto de 2014, 2 de marzo y 28 de junio de 2016, Exp. 16531, $19245,19412,19793$ y 18727 , respetivamente, consideró que en este evento, recae sobre el contribuyente una doble carga de la prueba. La primera, relativa a desvirtuar el indicio que se genera en su contra por la falta de aportación de la contabilidad, que vislumbra el incumplimiento de un deber de colaboración del contribuyente; $y$ la segunda, de soportar los costos y deducciones declarados. 
Para satisfacer la primera carga, el contribuyente debe demostrar que la contabilidad no fue aportada por causa de fuerza mayor o caso fortuito. Por su parte, la segunda se puede cumplir de dos formas: con la contabilidad cuando demuestre la ocurrencia de la fuerza mayor o caso fortuito, o con otros medios probatorios diferentes a la contabilidad, como las facturas. Pero la corporación no admite la pérdida de la contabilidad como una causal de fuerza mayor o caso fortuito, porque es un hecho previsible y, en todo caso, el contribuyente puede reconstruir los documentos contables con ayuda de los terceros con los que tiene relaciones comerciales. No obstante lo anterior, la Sala, con fundamento en sus facultades oficiosas y la sana crítica, consideró que es procedente valorar la contabilidad con otros soportes allegados en sede judicial-dictamen pericial, interrogatoriospara determinar la procedencia de los costos y deducciones declarados.

En tal sentido, la jurisprudencia de la Sala radica en la aplicación del sistema dispositivo, pero excepcionalmente da aplicación a las facultades inquisitivas del juez, para valorar con sana crítica las pruebas contables aportadas en la sede judicial con las demás medios probatorios recaudados en esa etapa procesal, como los dictámenes periciales, interrogatorios y facturas.

\section{Cuando el contribuyente no está obligado a llevar contabilidad}

El Consejo de Estado, Sección Cuarta, en las sentencias del 11 de enero de 2012, del 1 de noviembre de 2012 y del 7 de mayo de 2015, Exp. 18599, 18106 y 20580, respectivamente, señaló que estos contribuyentes solo tienen la carga de soportar los costos controvertidos por la DIAN con las facturas o documentos equivalentes, para que proceda el traslado de la carga probatoria a dicha entidad. Pero, además, se observó que si el contribuyente lleva contabilidad, a pesar de no estar obligado, luego no puede pretender que la misma no se tenga como prueba. Lo que es lógico teniendo en cuenta que el análisis de la prueba debe ser objetivo, y no partir de los intereses de la partes.

Todo lo dicho, refleja que la corporación aplicó el sistema dispositivo pues dejó en manos de los contribuyentes la responsabilidad de la aportación de las pruebas que soportan los costos y las deducciones.

\section{En los casos de presunciones, estimaciones e indicios}

El Consejo de Estado, Sección Cuarta, en las sentencias del 29 de abril de 2010, del 4 de agosto de 2011, del 10 de julio de 2014, del 8 de octubre de 2015 , del 12 de noviembre de 2015, del 15 de septiembre de 2016, del 2 de febrero de 2017 y del 19 de julio de 2017 Exp. 16891, 17628, 19782, 19495 , 19999, 20555, 20517 y 20981, respectivamente, indicó que estos mecanismos constituyen unos medios que relevan a la DIAN de probar ciertos hechos que se encuentra en dificultad de verificar en relación con el contribuyente.

Para ello, la DIAN debe partir de la demostración de los supuestos previstos en la ley para su aplicación. En el caso de las presunciones e indicios, además, se debe probar el hecho que permita inferir el que se pretende demostrar. Luego, la carga de la prueba se traslada al contribuyente, al que le corresponde desvirtuar el hecho que sustenta 
la aplicación de la presunción o los indicios recaudados por la Administración.

En el caso particular de los costos presuntos y estimados, la Sala precisó su alcance en el sentido de que solo aplican sobre los relacionados con la enajenación de activos, siempre que existan indicios de que el costo no es real, o no se conozca o no pueda establecerse con pruebas directas. Este último supuesto es el que permite su aplicación en los casos de los contribuyentes que no lleven en debida forma la contabilidad. Pero, también, es el que excluye de su aplicación, la falta de comprobación, porque esa hipótesis parte, precisamente, de la existencia de pruebas directas de los costos.

En todo caso, la Sala no define con precisión lo que debe entenderse por un costo que no sea real, o no se conozca, o que no pueda establecerse con pruebas directas, calificativos que no resultan tan claros ante el sinnúmero de situaciones que se pueden presentar en los soportes de los costos. Más todavía, cuando de los dos primeros no necesariamente se excluyen los supuestos de falta de comprobación o de cumplimiento de los requisitos legales de los soportes.

En cuanto a los indicios, la Corporación aceptó los indicios como una prueba capaz de desvirtuar por sí sola la contabilidad y las facturas o documentos equivalentes, con fundamento en que la apariencia de los documentos soportes que alleguen los contribuyentes no limitan la facultad de comprobación de la DIAN de verificar su realidad.

Pero lo cierto es que el criterio de la Sala es que si el contribuyente demuestra con pruebas idóneas, que no sean desvirtuadas por la DIAN, prevalecen esas pruebas frente a las presunciones, indicios y estimaciones.

Todo lo anterior demuestra que en estos aspectos el criterio jurisprudencial de la Sala sigue siendo la aplicación del sistema dispositivo, pues en las citadas providencias el análisis probatorio se limita al aportado por las partes sin que el juez ejerza una actividad probatoria de oficio. Sin embargo, se repite que, en estos casos, por tratarse de herramientas que le sirven a la DIAN para la determinación y cuantificación de la obligación tributaria, recae sobre esa entidad la carga de probar el cumplimiento de los supuestos de hecho para su aplicación, y luego se traslada al contribuyente, a fin de desvirtuar los elementos en que se fundó la Administración para la aplicación de tales recursos.

\section{En los casos de inspecciones tributarias, diligencias, requerimientos ordinarios y visitas de verificación}

El Consejo de Estado, Sección Cuarta, en las sentencias del 1 de noviembre de 2012 y del 13 de enero de 2016, Exp. 18106 y 22165 , respectivamente, señaló que las diligencias -inspecciones y visitas- y requerimientos ordinarios son una manifestación de la actividad de comprobación especial de la Administración que tiene por objeto recaudar las pruebas necesarias para verificar la veracidad de los datos declarados. Es decir, constituyen la forma como la DIAN ejerce la carga de la prueba, ya sea mediante la práctica de pruebas o mediante la solicitud de las mismas a los contribuyentes.

Este último supuesto implica el traslado de la carga al contribuyente, pues, en virtud de las facultades de fiscalización y con fun- 
damento en los deberes de colaboración de los contribuyentes, estos deben aportar los documentos soportes de los datos declarados, en especial las facturas y documentos en los que por ley deben constar los costos y deducciones. Pero en todo caso, para la Sala el hecho de que tales documentos no se alleguen en dichas diligencias, no impide que los mismos puedan ser valorados si se aportan dentro de las oportunidades probatorias en la vía administrativa, o en la judicial. Lo que se encuentra en concordancia con el sistema dispositivo que impone a las partes probar sus afirmaciones, aun durante el desarrollo del proceso judicial.

\section{Circunstancias especiales que deben probar los contribuyentes y dudas por vacíos probatorios}

El Consejo de Estado, Sección Cuarta, en las sentencias del 12 de abril de 2012, del 18 de octubre de 2012 y del 15 de junio y 19 de julio de 2017, Exp. 17734, 18329, 21864 y 20981, respectivamente, considera que las normas que regulan las circunstancias especiales y las dudas sobre vacíos probatorios, reconocen que el contribuyente es el que se encuentra en una posición privilegiada para probar los datos declarados, lo que permite aplicar sobre este la carga dinámica de la prueba. Que, como se dijo, viene siendo la misma aplicación del sistema dispositivo porque impone sin excepción alguna sobre el contribuyente la carga de probar los hechos declarados. Lo que ratifica la aplicación del sistema dispositivo.

Además, se encuentra que en el caso de vacíos probatorios, el criterio de la Sala condiciona la aplicación del artículo 745 del Estatuto Tributario a que las dudas por vacíos probatorios no deba referirse a hechos que deban ser probados por el contribuyente, y no solo las circunstancias especiales previstas en los artículos 786 a 791 ibídem, lo que restringe en gran medida la aplicación del citado artículo 745. Lo anterior se verifica en la revisión de las sentencias analizadas en este capítulo, en las que se encontró que ante la existencia de vacíos probatorios, en ningún caso la Sala dio aplicación del artículo 745 del Estatuto Tributario. Por el contrario, frente a dicha norma la Sección dio prevalencia a la exigencia que existe sobre el contribuyente de soportar los costos y deducciones declarados.

\section{En los casos en que el contribuyente allegue o solicite pruebas en los recursos}

El Consejo de Estado, Sección Cuarta, en las sentencias del 5 de septiembre de 2013, 12 de noviembre de 2015, 30 de agosto de 2016 y 20 de febrero de 2017, Exp. 18412, 19708, 20591 y 21089 , respectivamente, manifiesta que en aquellos casos en los que el contribuyente allegue pruebas en las respuestas o los recursos, la carga de la prueba recae en la DIAN, siempre que tales documentos soporten los costos y deducciones declarados conforme con lo dispuesto en la ley. Pero para la Sección, en ningún caso, la solicitud de decreto o práctica de una prueba que realiza el contribuyente suple su actividad probatoria ni le traslada la carga de la prueba a la Administración, porque sobre el obligado fiscal recae la responsabilidad de aportar los documentos soportes de los costos o deducciones, tanto en la vía administrativa como en sede judicial. De ahí que la falta de pronunciamiento por parte de la Administración o del juez de una prueba solicitada por el contribuyente no impide resolver el asunto de fondo, aplicando la carga 
de la prueba sobre el contribuyente por falta de actividad probatoria, siempre que la decisión judicial y/o administrativa se encuentre soporta probatoriamente. Lo que vislumbra la aplicación del sistema dispositivo.

\section{En los casos que se alleguen pruebas de terceros}

El Consejo de Estado, Sección Cuarta, en las sentencias del 9 de abril del 2015, 8 de septiembre de 2016 y 1 de marzo de 2017 , Exp. 19785,18945 y 21864 , respectivamente, encontró que las pruebas que se alleguen de terceros tienen la virtualidad de controvertir la contabilidad y las facturas aportadas por el contribuyente. Por tanto, las pruebas de terceros trasladan la carga de la prueba a la parte contra la cual se presenten, pero siempre que cumplan los requisitos de ley, y la contabilidad de dichos terceros no hubiese sido controvertida por la DIAN.

La Sala también fue enfática en señalar que la falta de colaboración o la imposibilidad por dificultades administrativas de los terceros para allegar a las oficinas de impuestos los soportes internos y/o externos, no invierte la carga de la prueba que radica en el propio contribuyente soportar la realidad de los costos.

En tal sentido, la Sección explicó que el tercero no tiene ninguna responsabilidad probatoria en el proceso, por lo que el hecho de que no aporte las pruebas solicitadas o las allegue parcialmente, no cambia la responsabilidad que recae sobre la demandante de probar los datos declarados.

Así las cosas, para la Sala, la falta de colaboración o de aportación de prueba de los terceros no invierte la carga de la prueba sobre una de las partes o la impone sobre dicho tercero, porque tanto en el procedimiento tributario como el judicial esa carga probatoria recae sobre las partes intervinientes.

\section{En los casos de requisitos generales y especiales de los costos y deducciones}

El Consejo de Estado, Sección Cuarta, en las sentencias del 26 de octubre de 2009, del 19 de agosto de 2010 y del 12 de diciembre de 2014, Exp. 16761, 16750 y 19261, respectivamente, establece el criterio jurisprudencial de la Sala en aplicar el sistema dispositivo para determinar la carga probatoria de los requisitos generales -artículo 107 del Estatuto Tributario-y de los especiales de cada deducción, porque la ratio decidendi o la razón de la decisión de las providencias se concretó en que tales presupuestos debían ser probados por el contribuyente por tratarse de una regla exceptiva que, como tal, exige una comprobación especial respecto de los contribuyentes.

Analizados los criterios de la carga de la prueba en el marco del procedimiento administrativo tributario, a continuación se estudiarán las reglas de la carga de la prueba que la Sala ha desarrollado en sede judicial, esto es, cuando el contribuyente demanda los actos de determinación y discusión del tributo ante la jurisdicción contenciosa administrativa.

\section{B. Jurisprudencia del Consejo de Estado sobre la carga de la prueba en sede judicial}

Respecto de la carga de la prueba en el proceso judicial, la Sección Cuarta del Consejo 
de Estado, Sección Cuarta, en auto del 23 de abril de 2009 y las sentencias del 26 de octubre de 2009, del 19 de agosto de 2010, del 5 de diciembre de 2011, del 1 de marzo de 2012, del 24 de mayo de 2012, del 7 de noviembre de 2012, del 21 de agosto de 2014 y del 6 de agosto de 2015, Exp.17508, 16585, 16236, 18327, 17568, 18766, 18574, 19412 y 20130 , respectivamente, parte de considerar que el judicial es un proceso diferente al procedimiento tributario, porque la discusión se enmarca en el proceso de nulidad y restablecimiento del derecho, que por disposición legal establece nuevas etapas probatorias tanto para el demandante -contribuyente-como el demandado-DIAN-.Pero esa posibilidad se condiciona a la aptitud de las pruebas; de ahí que el juez no admita aquellas que sean ilegales, innecesarias, superfluas o impertinentes.

Además, se observa que el juez es muy estricto en la admisión de pruebas en segunda instancia, pues si no cumplen con los presupuestos del C.C.A., hoy CPACA, no las valora como prueba, por respeto al derecho de defensa de la contraparte. De igual forma, se advierte que en la revisión de las sentencias proferidas por la Sala en el período analizado, no se encontró que hubiere desplegado sus facultades oficiosas para resolver la incertidumbre probatoria presentada en el análisis de los costos y deducciones en el impuesto de renta. Esa potestad solo fue utilizada como juez instructor de procesos para la valoración de la oportunidad y conducencia de las pruebas aportadas por las partes.

Lo que permite afirmar que el criterio de la Sala se enmarca más en el sistema dispositivo, pues impone sobre las partes la obligación de probar sus afirmaciones, y se limita a tomar la decisión con las pruebas allegadas por aquellas.

De todo lo expuesto, se concluye que tanto en el sede administrativa como la judicial, el sistema dispositivo es la regla general en la jurisprudencia del Consejo de Estado sobre la carga de la prueba en costos y deducciones. Solo en casos excepcionales, la corporación dio aplicación a la carga dinámica de la prueba, pero para establecer que el contribuyente es el que se encuentra en una posición favorable en el soporte de tales erogaciones; y desplegó sus facultades oficiosas, con la única finalidad de ejercer un control sobre las pruebas allegadas por las partes procesales.

De las sentencias estudiadas se desprende que la carga de la prueba no se limita a una actuación, sino que existe una dinámica de permanente contradicción entre la Administración y el contribuyente que se va desplegando en cada etapa, de acuerdo con las pruebas recaudadas o solicitadas por la DIAN y las allegadas por el administrado.

Sin embargo, en aquellas situaciones en las que a pesar de la labor del contribuyente y la Administración persisten los vacíos probatorios, la Sección establece la consecuencia negativa sobre aquel, por considerar que sobre los costos y deducciones recae una comprobación especial.

Esa posición, sobre todo, tiene el propósito de establecer sobre el obligado tributario la carga de aclarar todos los vacíos probatorios, lo que desconoce que precisamente el artículo 745 del Estatuto Tributario impide que se imponga sobre los contribuyentes la consecuencia negativa de la carga de la prueba, en aquellos casos en que la DIAN no 
pueda eliminar dicha incertidumbre, a excepción de que tales vacíos recaigan sobre las circunstancias especiales de que trata el capítulo III del Título VI.

A esa discusión se suma que la Sección le ha dado prevalencia a la prueba de terceros sobre la del contribuyente, al punto de desconocer su contabilidad y demás soportes de los costos y deducciones. Situación que limita la carga probatoria del obligado tributario para soportar los datos declarados.

En los demás casos, también fue uniforme la posición jurisprudencial en establecer la carga de la prueba bajo el sistema dispositivo y, en particular, sobre la parte demandante contribuyente, básicamente porque la de los costos y deducciones es una regla exceptiva y en atención a lo dispuesto en el artículo 177 del C.P.C. solo en algunos casos trasladó la carga a la DIAN, cuando el contribuyente aportó documentos que no hubieren sido desvirtuados por aquella, lo que sucede en pocas ocasiones.

Luego de este análisis, se procede a realizar la agrupación de las reglas de la carga de la prueba que fueron identificadas en el primer capítulo relativo a las normas jurídicas - procesales y tributarias-y en el segundo capítulo, que concreta la posición de la jurisprudencia en esta materia.

\section{Valoración y agrupación de las reglas de la carga de la prueba de los costos y deducciones, identificadas en la normativa tributaria y procesal, y en la jurisprudencia}

A partir del estudio de las citadas normas jurídicas y la jurisprudencia, se presenta una concreción de criterios de la carga de la prueba que consideramos que aplican en materia de los costos y deducciones en el impuesto de renta.

\section{A. Regla general: el criterio de la carga afirmativa}

Este criterio hace referencia al sistema dispositivo que impone a las partes la prueba de sus afirmaciones. Esta regla general fue establecida en la norma procesal en materia probatoria (artículo 167 CGP) y aplicada en la jurisprudencia del Consejo de Estado analizada.

De las citadas providencias se puede concluir que es uniforme el precedente jurisprudencial de la Sección Cuarta de la citada corporación, en aplicar el sistema dispositivo para establecer la procedencia de los costos y deducciones. Solo en casos excepcionales, la Sala llegó al grado de certidumbre necesario para tomar una decisión, mediante la aplicación de la carga dinámica de la prueba o invocando sus facultades oficiosas.

Pero la alta corporación no utiliza sus facultades oficiosas para lograr el grado de certidumbre en las discusiones probatorias de estos conceptos, pues en ninguno de los casos de las sentencias verificadas se observó la práctica de prueba de oficio. Solo desplegó tal potestad para ejercer un control sobre la valoración de las pruebas allegadas por las partes, y no para complementar las mismas en los casos de vacíos probatorios. Lo que da entender que, para la Sala, la facultad oficiosa no puede utilizarse para suplir la actividad probatoria de las partes. También se observó que la aplicación de la carga dinámica de la prueba se hizo bajo el 
mismo criterio del sistema dispositivo, porque siempre aplicó sobre el contribuyente la carga de la prueba de los costos, por tener mayor acceso a la prueba de los costos y deducciones.

Así las cosas, consideramos que en materia tributaria, la aplicación de esta regla general, esto es, del sistema dispositivo, se presenta en relación con el contribuyente y la Administración, con los siguientes matices:

\section{La DIAN tiene la carga de la compro-} bación especial. Esto aplica tanto para desvirtuar la presunción de veracidad de las declaraciones tributarias o de las respuestas $\operatorname{administrativas~}^{24}$, como para determinar la obligación del contribuyente omiso. Es decir, lo que se ha considerado la prueba de los hechos constitutivos de la obligación tributaria.

En relación con este supuesto, el Consejo de Estado señaló que la actividad de comprobación podía ejercerse con la simple solicitud de los soportes de los datos declarados o con el recaudo de pruebas, mediante las herramientas que le otorga el Estatuto Tributario a la Administración para desplegar esa facultad, tales como requerimientos ordinarios, inspecciones tributarias, visitas de verificación, interrogatorios y demás medios de prueba autorizados por la ley.

\section{El contribuyente tiene la carga de pro-} bar los costos y deducciones declarados mediante la aportación de la factura, o documento equivalente, o documento autorizado por el Gobierno Nacional. Una vez desvirtuada la presunción de veracidad o determinada la existencia de la obligación tributaria por parte de la DIAN, el contribuyente debe soportar los costos y deducciones con la tarifa probatoria establecida en el artículo 771-2 del Estatuto Tributario. Lo que ha sido denominado como la prueba de los hechos exceptivos, que recaen sobre los contribuyentes por tratarse de conceptos que aminoran la obligación tributaria.

En esta carga, no solo se soporta en la tarifa probatoria prevista en la ley sino también en el deber de colaboración que tienen los contribuyentes respecto de la DIAN, de aportar los soportes y explicaciones requeridos por la Administración en los actos administrativos o diligencias.

3. El contribuyente tiene la carga de aportar la prueba contable. En el caso de los contribuyentes obligados a llevar contabilidad, la Sala ha señalado que el artículo 781 del Estatuto Tributario establece sobre aquellos una doble carga probatoria. La primera, de desvirtuar el indicio en su contra por no presentar los documentos contables -hechos constitutivos de fuerza mayor o caso fortuito- $y$, la segunda, de soportar los costos y deducciones mediante pruebas adicionales a la contabilidad, que pueden ser aportadas o solicitadas en la vía administrativa o judicial.

En caso de que no se cumpla es carga, el artículo 781 ibídem de manera explícita

\footnotetext{
${ }^{24}$ Recuérdese que de conformidad con el artículo 746 del Estatuto Tributario, los hechos consignados en las declaraciones tributarias y en las respuestas administrativas gozan de presunción de veracidad, hasta que son controvertidos por la dian.
} 
dispone una consecuencia negativa sobre el contribuyente, consistente en el desconocimiento de los costos y deducciones.

\section{El contribuyente tiene la carga de} aportar las pruebas especiales exigidas en Estatuto Tributario. Es el caso de las circunstancias especiales que deben probar los contribuyentes previstas en los artículos 786 a 791 del Estatuto Tributario, y de otras normas sobre costos y deducciones que de forma expresa sujetan su procedencia a que el contribuyente pruebe ciertos hechos.

Estas últimas, son las referidas a las deducciones por pagos al exterior (artículo $123 \mathrm{del}$ E.T) y por deudas manifiestamente pérdidas o sin valor (artículo 146 del E.T.), los costos o deducciones por pagos negados por los beneficiarios (artículo 787 del E.T.)

\section{La Administración, para sustentarse en} indicios, presunciones o estimaciones debe soportar los supuestos para su aplicación, y el contribuyente, desvirtuarlos. Los indicios, presunciones y estimaciones son instrumentos que ostenta la DIAN para ejercer la carga probatoria, cuando tiene la dificultad de verificar ciertos hechos, en aquellos casos en que el contribuyente no aporte la prueba suficiente.

Consideramos que estas herramientas no solo permiten a la DIAN desvirtuar la presunción de veracidad de la declaración, sino también trasladar al contribuyente una doble carga probatoria. La primera, en relación con la prueba de los costos y deducciones, y la segunda, referente a desvirtuar los indicios, presunciones, estimaciones, o las pruebas recaudadas en su contra en las diligencias practicadas por la Administración.
De acuerdo con el objeto de este estudio, interesa detenerse en los costos estimados y presuntos previstos en el artículo 82 del Estatuto Tributario, que proceden en aquellos casos en que no exista certeza de la erogación por venta de activos enajenados. Pero conforme con la jurisprudencia analizada, esa incertidumbre no debe generarse por la falta de aportación de prueba y debe existir certeza de la venta del activo enajenado. Todo porque la norma condiciona su aplicación a que el costo informado no sea real o no se conozca ni sea posible su determinación con pruebas directas, como las declaraciones de renta, la contabilidad o los comprobantes internos y externos.

\section{En los casos que el contribuyente reali-} ce una confesión, sobre este recae la carga de desvirtuarlo en los casos que aluda error o equivocación. Conforme con los artículos 747 y 748 del Estatuto Tributario, el contribuyente confeso debe demostrar la prueba del error o fuerza de este, o el dolo de un tercero o la falsedad material del escrito contentivo de la confesión.

7. La carga de la prueba expedida por terceros. La jurisprudencia analizada exime de cualquier responsabilidad a los terceros en cuanto a la aportación de prueba -ya sea total o parcial-, pero, en todo caso, le ha dado mayor relevancia a la prueba de aquel, a tal punto que con fundamento en ella ha desvirtuado la contabilidad y las facturas allegadas por los contribuyentes. Lo que deja al contribuyente en una situación de dificultad probatoria, pues, es esos casos, se limita en gran medida el acervo probatorio que puede este aportar para soportar su afirmación y desvirtuar la información de dicho tercero. 
En efecto, al desconocérsele al contribuyente la prueba contable, que es plena prueba y la idónea para soportar la declaración tributaria, se presenta el siguiente cuestionamiento: ¿qué prueba le queda al contribuyente para soportar su afirmación, si se le ha quitado el valor probatorio a su contabilidad y de los soportes de la misma, más todavía cuando los documentos aportados por el tercero, a excepción de la facturas o documentos equivalentes, por lo general, se encuentran en poder de dicho tercero?

En estos eventos, se considera que no debería establecerse de forma categórica que los documentos de terceros tienen mayor valor probatorio que los aportados por el contribuyente, sino que esa situación debe sopesarse con fundamento en la veracidad de la contabilidad y los medios probatorios aportados por tales sujetos.

No puede perderse de vista que el tercero no tiene ningún interés en el proceso, lo que sí sucede con el contribuyente, que como parte procesal es el que podría sufrir la consecuencia negativa del juicio, como es la de verse afectado con la imposición de un mayor impuesto. La idea no es invertir la carga de la prueba sobre un tercero, sino que se realice una valoración en conjunto de las pruebas allegadas por el contribuyente $y$ por aquel, a fin de llegar a la verdad de los hechos, para lo cual se sugiere tener en cuenta la tarifa probatoria dispuesta en la ley, y el tipo de prueba allegada, si es documental de carácter público, privado o contable, o testimonial o indiciaria, para que al final se dé prelación probatoria a aquella que tenga mayor valor legal para soportar el hecho discutido.
El otro evento es cuando la prueba en poder del tercero no es aportada. En esos casos, la Sección radica la responsabilidad en el contribuyente, con fundamento en que sobre las partes del proceso es que recae la carga probatoria. No obstante lo anterior, se considera que el contribuyente no debe soportar la carga de aportar toda prueba expedida por un tercero, sino únicamente aquella que sea suscrita por ambos, o la relativa a las facturas o documento equivalente, que por disposición legal debe poseer como respaldo de sus costos y deducciones. Esto, porque existen casos en los que el contribuyente no tiene en su poder los documentos expedidos por el tercero, ya sea porque en la práctica comercial y/o por disposición legal no está en la obligación de exigir. Pero, cuando por alguna circunstancia la prueba es exigida por la Administración en desarrollo de un proceso de fiscalización, debe solicitársela al tercero y quedar a la expectativa de que la misma sea aportada.

Lo anterior, porque el contribuyente no cuenta con herramientas coercitivas para exigir al tercero la aportación de la prueba, como sí la tiene la DIAN en su calidad de autoridad tributaria, mediante sus amplias facultades de fiscalización, que no solo le permiten obtener la prueba sino verificar la misma de forma directa en la contabilidad del tercero. Entender lo contrario, dejaría al obligado tributario en una posición desfavorable cuando se le exige una prueba expedida por un tercero y este se niega a aportarla.

En los demás casos, esto es, la prueba expedida de tercero en el que el contribuyente hubiere intervenido, o que por disposición legal y/o por costumbre comercial debe exigir copia al tercero, la carga de la 
prueba recae sobre el contribuyente porque se trata de una soporte que debía conservar para respaldar sus obligaciones tributarias o comerciales.

De todo lo expuesto, puede concluirse que la regla general de la carga de la prueba es el sistema dispositivo y, en tal sentido, sobre las partes recae la responsabilidad de la aportación de las pruebas que soportan sus afirmaciones. Pero, además, esa responsabilidad se distribuye dentro de la dinámica probatoria que se da en el procedimiento administrativo tributario y el proceso contencioso administrativo. Por un lado, la Administración debe demostrar las irregularidades que desvirtúan la presunción de veracidad de la declaración $y$, por el otro, al contribuyente le corresponde la prueba de los costos y deducciones requerida por la DIAN.

Pero existen excepciones a la distribución de la carga de la prueba estudiada, que demuestran que no en todos los casos la parte debe demostrar su afirmación, sino que esa carga puede invertirse, por ejemplo, por condiciones de facilidad en la aportación de la prueba o dada la existencia de vacíos probatorios en la modificación del tributo, como pasa a estudiarse a continuación.

\section{B. Excepción a la regla general: la carga dinámica de la prueba, la carga de la duda probatoria y la regla de la no carga de la prueba de los hechos aceptados por los contribuyentes en las respuestas}

De acuerdo con lo dispuesto en las normas tributarias y procesales, y la jurisprudencia, se advierten los siguientes criterios exceptivos de la regla general de la carga de la prueba anteriormente analizada.
1. La carga dinámica de la prueba. La jurisprudencia del Consejo de Estado estudiada aplicó de forma excepcional la carga dinámica de la prueba, pero bajo el mismo criterio del sistema dispositivo, pues parte de establecer que es el contribuyente el que se encuentra en una posición más privilegiada para probar los costos y deducciones y, por tanto, sobre este recae la carga probatoria. En tal sentido, la aplicación de la carga dinámica de la prueba recae sobre el contribuyente.

No obstante, consideramos que en el proceso contencioso administrativo debe darse aplicación a las reglas de juicio de la carga dinámica de la prueba dispuestas para los jueces en el artículo 167 del CGP, dada la remisión del artículo 211 del CPACA.

En tal sentido, durante cualquier momento procesal antes de dictar sentencia, el juez administrativo tiene facultades de distribuir la carga de la prueba sobre alguna de las partes que se encuentre en una situación más favorable para aportarla. Las reglas de juicio consagradas en la norma para que el juez determine que una parte se encuentra en una posición favorable se concretan en el grado de cercanía con la prueba, por poseer el objeto de la prueba, por circunstancias técnicas especiales, por haber intervenido en los hechos, por estado de indefensión o incapacidad de la contraparte, u otras circunstancias similares.

2. La carga de la duda probatoria. Este criterio corresponde al señalado en el artículo 745 del Estatuto Tributario, según el cual las dudas provenientes de vacíos probatorios se resuelven a favor del contribuyente, salvo que este se encuentre obligado a probar determinados hechos de acuerdo con las normas 
del capítulo III del título VI -circunstancias especiales que debe probar el contribuyente-.

El criterio jurisprudencial del Consejo de Estado condiciona la aplicación de esa norma a que las dudas por vacíos probatorios no se refieran a cualquier hecho que deba ser probado por el contribuyente, y no solo a las circunstancias especiales previstas en los artículos 786 a 791 del Estatuto Tributario, restringiendo en gran medida la aplicación del artículo 745 ibídem. Lo que se ratifica en que en ninguna de las sentencias analizadas se observó la aplicación al aludido artículo 745 , ni por parte de la Administración ni por la jurisdicción.

Con esa interpretación se extiende la prohibición de la aplicación del artículo 745 del Estatuto Tributario a casos no contemplados en la ley, como son los hechos sobre los cuales recae la comprobación especial, lo que desconoce que la norma de forma expresa se refiere únicamente a las circunstancias especiales que deben probar los contribuyentes. No se trata de los mismos hechos, los relativos a la comprobación especial contemplan el requerimiento probatorio realizado por la DIAN y el previsto en la ley, y, en general, todas aquellas situaciones en que se exige al contribuyente la aportación de la prueba. Pero no toda comprobación especial puede considerarse una circunstancia especial que debe probar el contribuyente, pues estas últimas solo atienden a las definidas en los artículos 786 al 791 del Estatuto Tributario. Si se tratara de los mismos hechos, la ley hubiese exceptuado de la aplicación de la norma a todos los casos de comprobación especial, pero en su lugar se refirió exclusivamente a los hechos contemplados en el capítulo III del Título VI, que se denomina "Circunstancias especiales que deben ser probadas por los contribuyentes". Por lo que no se coincide con la interpretación restrictiva que realiza la alta corporación.

Por su parte, se encuentra que la doctrina, en particular el autor Zornoza Pérez (2006, pp. 35-36), señala que en el procedimiento tributario no existe la carga de la prueba porque no existe el non liquet, o él no está claro, dadas las amplias facultades de fiscalización que cuenta la Administración tributaria, que le permiten ejercer la carga probatoria de la parte, así como estimar o presumir los elementos de la obligación tributaria.

Sin embargo, se considera que el artículo 745 del Estatuto Tributario constituye una regla exceptiva de la carga de la prueba en el procedimiento administrativo tributario, porque impone sobre las partes una consecuencia negativa en los casos de vacíos probatorios.

Es por eso que en este escrito se plantea una interpretación diferente a la señalada por el citado autor y el precedente jurisprudencial de la Sala, que no solo nos lleva a concluir que en el procedimiento administrativo tributario sí existe la carga de la prueba, sino también que puede aplicarse la carga dinámica en ciertos casos y bajo los supuestos contemplados en el artículo 745. Recordemos la redacción de la norma ${ }^{25}$.

\footnotetext{
${ }^{25}$ Extraída del Estatuto Tributario contenido en la página Web de la Secretaría del Senado del Congreso de la República: http://www.secretariasenado.gov.co/senado/basedoc/estatuto_tributario_pr030.html\#745
} 
Artículo 745. Las dudas provienentes de vacíos probatorios se resuelven a favor del contribuyente. Las dudas provenientes de vacíos probatorios existentes en el momento de practicar las liquidaciones o de fallar recursos, deben resolverse, si no hay modo de eliminarlas, a favor del contribuyente, cuando este no se encuentre obligado a probar determinados hechos de acuerdo con las normas del capítulo III de este título ${ }^{26}$.

Como se observa, la situación abstracta que la norma prevé para su aplicación es que la DIAN: (i) al momento de proferir la liquidación oficial o de resolver los recursos advierta dudas por vacíos probatorios y (ii) tales dudas no las puedan eliminar. $\mathrm{La}$ consecuencia jurídica de esos supuestos es que las dudas deben resolverse a favor del contribuyente. A excepción de que los vacíos probatorios recaigan sobre las circunstancias especiales que deban probar los contribuyentes contempladas en el capítulo III del régimen probatorio.

Esta norma radica sobre la Administración la responsabilidad de ejercer el debido recaudo de las pruebas que sustentan su actuación administrativa. Es decir, le impone una consecuencia negativa por errores u omisiones en el ejercicio de la actividad de comprobación especial que genere la existencia de vacíos probatorios.

Ello se ratifica en el hecho de que la norma y su consecuencia negativa no se aplique en los casos de circunstancias especiales que deban probar los contribuyentes, por cuanto respecto de estas y, por disposición legal, el obligado tributario tiene la carga de la prueba, independientemente de la actividad probatoria que realice la DIAN.

Por lo anterior, se considera que la norma restringe a la Administración que profiera una liquidación oficial o resuelva recursos sin que exista certeza de la determinación de la obligación tributaria, a tal punto que lo condiciona al hecho de que si no puede aclararlo debe resolver las dudas a favor del contribuyente. Pero se precisa que, en todo caso, el vacío probatorio a que se refiere la norma no debe provenir de la falta de actividad probatoria del contribuyente, sino de la Administración. Precisamente, porque la consecuencia adversa se impone sobre la Administración por su omisión probatoria.

De tal manera que la regla de la carga de la prueba por duda probatoria se presenta cuando la decisión administrativa no está debidamente soportada por la DIAN y, ante la persistencia de esas dudas, aquella se debe resolver a favor del contribuyente, porque no resulta justo que se expida en contra del obligado tributario un acto administrativo que incurra en incertidumbre probatoria respecto de las pruebas que sustentan la modificación o la determinación oficial de los tributos.

Recuérdese que el procedimiento administrativo tributario es por esencia inquisitivo, dadas las amplias facultades de investiga-

\footnotetext{
${ }^{26}$ Las normas del Capítulo III del Título VI -Régimen probatorio- en el cual se encuentra el artículo 745, son las que regulan las circunstancias especiales que deben ser probadas por los contribuyentes.
} 
ción e instrucción de la DIAN, lo que lo inviste de prerrogativas y herramientas que le permiten desplegar una actividad probatoria para el debido recaudo de los tributos.

Pero esa facultad también obliga a la Administración a la búsqueda de la verdad de los hechos que dan lugar a la determinación del tributo, pues aunque cuenta con facultades para presumir y estimar algunos elementos de la obligación tributaria, las mismas son excepcionales y no aplican en todos los casos. De tal manera que no siempre puede evitar el non liquet, esto es, la incertidumbre probatoria, con las estimaciones o presunciones previstas en el Estatuto Tributario. Precisamente, la norma analizada reconoce que en la expedición de la liquidación oficial o de revolver el recurso pueden presentarse dudas o incertidumbre en los soportes de la obligación tributaria. Por lo que no se puede desconocer que en el procedimiento administrativo tributario puede existir incertidumbre probatoria.

Así las cosas, consideramos que el artículo 745 del Estatuto Tributario se encarga de castigar a la DIAN por no ejercer debidamente su actividad de comprobación especial, ya sea en la solicitud, recaudo o comprobación de las pruebas que generen dudas sobre la determinación de la obligación tributaria.

Todo ello no solo reconoce la existencia de la carga de la prueba en el procedimiento tributario, sino también de la carga dinámica de la prueba, porque la consecuencia negativa prevista en el artículo 745 del Estatuto Tributario se aplica porque la DIAN en su calidad de autoridad tributaria y en ejercicio de sus facultades de fiscalización no ejercició la actividad probatoria a pesar de todas las herramientas que se encontraban a su favor.

No puede perderse de vista que la DIAN cuenta con libertad probatoria para recaudar las pruebas que sustenten la determinación de la obligación tributaria, y tiene herramientas coercitivas para obtener información tributaria de varias fuentes -contribuyentes y terceros-, tales como el RUT, información exógena, inspecciones, visitas, requerimientos ordinarios, entre otros, que le permiten no solo desvirtuar la presunción de veracidad de la declaración, sino también sustentar su actuación administrativa de revisión de los tributos.

\section{No existe carga de la prueba de los} hechos aceptados por los contribuyentes en los recursos. De conformidad con el artículo 723 del Estatuto Tributario, los hechos que acepten los contribuyentes en los recursos no pueden ser objetados por este. Por tanto, ni el contribuyente ni la DIAN tienen la carga de probar tales supuestos. Pero es evidente que la consecuencia negativa de tal aceptación es en contra del contribuyente, porque se tiene como una confesión.

De acuerdo con lo expuesto, se encuentra que existen circunstancias especiales que imponen sobre una de las partes la consecuencia negativa por la existencia de incertidumbre probatoria en la determinación de los costos y deducciones. Eventos en los que se vislumbra la aplicación de los principios de justicia, lealtad procesal de las partes y colaboración con el buen funcionamiento de la administración de justicia.

Todo porque, a pesar de que sobre una de las partes recae en principio la carga pro- 
batoria, estas reglas exceptivas permiten observar qué sujeto procesal se encuentra en una posición más favorable para aportar la prueba en el proceso.

Lo mismo sucede en el caso de los vacíos probatorios por irregularidades en la actividad de comprobación especial, que permiten imponer la consecuencia negativa sobre la DIAN por no haber ejercido las facultades y herramientas inquisitivas que le otorgó la ley para sustentar la modificación del tributo. Criterio que reitera el deber de lealtad procesal de las partes y de motivación de la actuación administrativa.

Esta última circunstancia exceptiva -vacíos probatorios- es la que lleva a sostener que la carga dinámica de la prueba no solo aplica en el proceso contencioso administrativo, sino también en el procedimiento administrativo tributario.

\section{Conclusiones}

La carga de la prueba es un principio de carácter procesal que informa a las partes su responsabilidad probatoria y le da la posibilidad al juez de decidir de fondo un proceso cuando existen vacíos probatorios, a fin de evitar la expedición de fallos inhibitorios.

En el procedimiento tributario, la carga de probar se pone en funcionamiento con la presunción de veracidad que ampara la declaración tributaria o con el acto en el que la Administración establece la obligación tributaria-en los eventos en que no se presenta declaración-y, en ambos casos, culmina con la resolución de la DIAN que da fin a la vía administrativa y que pone en evidencia la incertidumbre sobre la procedencia de los costos y deducciones. Por su parte, en el proceso contencioso administrativo promovido contra esos actos, la responsabilidad probatoria se manifiesta desde las primeras actuaciones de las partes, la demanda y la contestación de la demanda, y solo en ciertas situaciones con las pruebas allegadas en segunda instancia o las pruebas de oficio.

Es así como las normas tributarias y procesales establecen como regla general la carga de la prueba sobre las partes, y como excepción, las facultades oficiosas del juez y la aplicación de la carga dinámica de la prueba. Estas últimas, con la finalidad de encontrar la verdad real de los hechos y de propender por la aplicación de los principios de igualdad, de equidad y lealtad procesal.

Bajo ese mismo criterio, el Consejo de Estado ha mantenido una posición uniforme que propende por la aplicación del sistema dispositivo en la determinación de la carga de la prueba de los costos y deducciones, con la consideración de que esos conceptos que aminoran la carga tributaria están sujetos a una comprobación especial por parte del contribuyente. Lo que ha llevado a que la alta corporación restrinja la aplicación de la carga dinámica de la prueba y sus facultades oficiosas previstas en la ley.

En ese contexto, se agruparon ciertos criterios en los que se analizó la dinámica probatoria de las partes y se identificó sobre cuál de ellas recaía la responsabilidad de probar dependiendo de las obligaciones procesales y tributarias impuestas sobre las mismas. A partir de ese estudio, se realizaron ciertas críticas a la jurisprudencia, en particular, en lo atinente a las pruebas allegadas por los terceros y dudas por vacíos probatorios. 
A. En primer lugar, se estableció una regla general relativa al sistema dispositivo $\mathrm{y}$, unas excepciones concernientes a la carga dinámica de la prueba, la duda por vacíos probatorios y la regla de no carga de la prueba.

La regla general referente al sistema dispositivo establece sobre las partes la responsabilidad de probar su respectiva afirmación o excepción. Este criterio no solo está dispuesto en las normas tributarias en materia probatoria -82 (costos presuntos); 123 (deducción por pagos en el exterior); 146 (deudas manifiestamente pérdidas o sin valor); 714 (presunción de veracidad); 744 (oportunidad para allegar prueba por los contribuyentes); 755, 756, 757, 758, 759, 760 (presunciones en materia tributaria); 754, 754-1 (indicios para determinar ingresos, costos y deducciones); 772, 773, 774 y 781 (prueba contable); 786- 791 (circunstancias especiales que deben probar los contribuyentes); 686 (requerimientos ordinarios), sino también en las normas procesales aplicables en materia tributaria -artículo 167 del CGP-.

En la aplicación de esta regla general se precisó la responsabilidad de cada parte, así:

1. La DIAN tiene la carga de la comprobación especial. En los casos en que los contribuyentes presentan la declaración tributaria, estén o no obligados a llevar contabilidad, la carga de la prueba recae sobre la DIAN, para desvirtuar la presunción de veracidad de la declaración mediante la actividad de comprobación, y respecto del contribuyente, en cuanto a la aportación de la prueba de los costos y deducciones controvertidos por la Administración.
Por su parte, en los casos en que el procedimiento tributario inició sin la presentación de una declaración, la DIAN tiene la carga de probar la existencia de la obligación, el obligado, y la cuantía. Por su parte, sobre el contribuyente se estableció la carga de desvirtuar la existencia y la determinación de la obligación tributaria efectuada por la Administración.

La regla de la carga probatoria en las inspecciones tributarias, diligencias, requerimientos ordinarios y visitas, consiste en que sobre la DIAN recae la obligación de ejercer en estas la comprobación especial $\mathrm{y}$, en el contribuyente, el deber de colaboración de aportar los soportes y explicaciones requeridos por la Administración en tales diligencias.

Por su parte, en los casos de las pruebas allegadas por el contribuyente, el criterio consiste en que solo trasladan la carga a la DIAN cuando resultan conducentes para probar los costos y deducciones. Y las solicitadas por aquel no suplen su carga probatoria en tanto sobre el contribuyente recae la obligación de aportar los soportes de las citadas erogaciones. (Artículos 714, 744 y 686 del E.T.).

2. El contribuyente tiene la carga de probar los costos y deducciones mediante la factura, documento equivalente o el documento autorizado por el Gobierno Nacional; tarifa probatoria establecida en el Estatuto Tributario para que proceda la solicitud de costos y deducciones, que sean controvertidos por la DIAN. (Artículo 771-2 del E.T.).

3. El contribuyente tiene la carga de aportar la prueba contable. En el caso de los con- 
tribuyentes obligados a llevar contabilidad, existe una doble carga probatoria, la primera para desvirtuar el indicio en su contra por no presentar la declaración y, la segunda, de desvirtuar los costos y deducciones mediante pruebas adicionales a la contabilidad. (Artículo 772-7774 y 781 del E.T.).

4. El contribuyente debe aportar las pruebas especiales contempladas en la ley, como las previstas en los artículos 123 (deducción por pagos en el exterior), 146 (deudas manifiestamente perdidas o sin valor) y 786-791 (circunstancias especiales que deben probar los contribuyentes).

5. En relación con la aplicación de presunciones, estimaciones e indicios, la carga de la prueba se aplica bajo el criterio que corresponde a la DIAN probar los supuestos para su aplicación y al contribuyente la de desvirtuar la existencia del hecho indicador. (Artículos 82 y 755-760 del E.T.).

6. En los casos de confesión del contribuyente, sobre este recae la carga de demostrar que lo manifestado se deriva de un error o equivocación. (Artículo 747 y 748 del E.T.).

7. Respecto de la carga de terceros, se plantearon algunas críticas a la posición de la jurisprudencia en torno a ese tema. En estos casos, el Consejo de Estado dio mayor valor probatorio a la prueba de terceros que a la allegada por el contribuyente y, además, eximió de cualquier responsabilidad probatoria a aquellos. Frente a esta consideración, se dijo que no debería tomarse como plena prueba la aportada por el tercero, sino valorarla con la allegada por el contribuyente, a fin de tener como prueba la que tenga mayor valor legal para probar el hecho incierto. También se precisó que no en todos los casos se debe imponer sobre el contribuyente la carga de aportar un documento expedido por un tercero, sino únicamente cuando aquel hubiere intervenido en su formación, o se trate de soportes que por ley o práctica comercial debería tener en su poder. En los demás casos, se planteó que la carga de la prueba corresponde a la DIAN, pues esta cuenta con las herramientas coercitivas necesarias para exigir a un tercero la aportación de documentos de carácter tributario.

B. En segundo lugar, se plantearon unas excepciones al sistema dispositivo, que se concretan en la carga dinámica de la prueba, la duda por vacíos probatorios y la regla de la no carga probatoria.

En cuanto a la aplicación de la carga dinámica de la prueba, se precisó que conforme con la remisión que realiza el artículo 211 del CPACA a las normas de procedimiento civil en materia probatoria, debe darse aplicación a las reglas de juicio consagradas en el artículo 167 del C.G.P. y que permiten establecer cuándo una parte se encuentra en una situación favorable para aportar la prueba. Esas reglas dependen de la proximidad que se tenga con la prueba, por tenerla en su poder, de circunstancias técnicas, por la intervención en los hechos, por estado de indefensión, o incapacidad de la contraparte, entre otras.

En relación con la duda por vacíos probatorios, se puso de presente que la Sala restringe su aplicación no solo a las circunstancias especiales que deben probar los contribuyentes sino a todo hecho que deba 
ser probado por estos, lo que hace imposible su aplicación en la realidad.

En este artículo se plantea una interpretación diferente a la realizada por el Consejo de Estado y por la doctrina, pues se sugiere que el artículo 745 del Estatuto Tributario constituye una verdadera regla de la carga de la prueba, toda vez que ante la existencia de un hecho incierto, la ley le impone a la Administración la obligación de decidir en favor del contribuyente, en los casos en los que del vacío probatorio se deriven de errores u omisiones en la actividad de comprobación especial de la DIAN. A excepción de que el vacío probatorio provenga de las circunstancias especiales que deben probar los contribuyentes.
En esos casos, en que la incertidumbre generada por fallas en la actividad de fiscalización no pueda ser superada la DIAN, esta debe abstenerse de expedir la liquidación oficial o la resolución que resuelva el recurso de reconsideración, y expedir un auto de archivo en el que se decida a favor del contribuyente.

Precisamente, con fundamento en esa norma es que en este artículo se concluye que en el procedimiento adminitrativo tributario sí existe la carga de la prueba, y además, la misma se impone de forma dinámica, porque se establece sobre una parte-la DIAN- la consecuencia negativa por encontrarse en una posición favorable probatoria -facultades de comprobación especial otorgadas en la ley-. 


\section{Bibliografía}

\section{Doctrina}

Betancur Jaramillo, C. (2013). Derecho procesal administrativo. Medellín: Señal Editora.

Benavides, J.L. (2016). Código de Procedimiento Administrativo y de lo Contencioso Administrativo comentado y concordado. Bogotá: Universidad Externado de Colombia.

Cermeño, C. C.; De Bedout, J. C.; Andrés García, S. y Clopatofsky, C. M. (2016). Procedimiento Tributario, Teoría y práctica. Bogotá: Legis.

Devis Echandía, H. (2012). Teoría General de la Prueba Judicial. Bogotá: Temis.

Palacio Hincapié, J. A. (2004). Derecho Procesal Administrativo: la prueba judicial. Tomo I. Bogotá: Ediciones Doctrina y Ley.

Hensel, A. (2005). Derecho Tributario (Báez M., trad.). Madrid: Marcial Pons.

Jaramillo, C. B. (1982). De la prueba judicial. Medellín: Dike.

López Blanco, H. (2008). Instituciones de Derecho procesal colombiano. Tomo III Pruebas, Bogotá. DUPRE.

Michelli, G. A. (1989). La carga de la prueba (S. S. Melendo, trad.). Bogotá: Temis.

Parra Quijano, J. R. (2014). Manual de Derecho probatorio. Bogotá: Librería Ediciones el Profesional Ltda.

Piza Rodríguez, J. R (2016). Análisis crítico de la reforma tributaria, Ley 1819 de 2016. Bogotá: Universidad Externado de Colombia.

Piza Rodríguez, J. R. (2010). Curso de Derecho tributario, Procedimiento y Régimen Sancionatorio. Bogotá: Universidad Externado de Colombia.

Piza Rodríguez, J. R. (2011). El impuesto sobre la renta y complementarios. Bogotá: Universidad Externado de Colombia

Rodríguez-Bejeiro, M. (2011). La carga de la prueba en el Derecho tributario: su aplicación en las normas tributarias antiabuso y en la doctrina del TJUE. Madrid: Universidad Autónoma de Madrid.

Rosenberg, I. (1956). La carga de la prueba. 2. (E. Krotoschin, trad.). Argentina: Ediciones Jurídicas Europa - Ámerica.

Whittingham García, E. (2005). Las pruebas en el proceso tributario. Bogotá: Editorial Temis.

Zornoza Pérez, J. (2006). "La prueba en el Derecho tributario", en Memorias XXX Jornadas Colombianas de Derecho Tributario. Bogotá. ICDT.

\section{Jurisprudencia}

Corte Constitucional. Sentencia C-086 de 2016.

Consejo de Estado, Sección Cuarta, Sentencia del 23 de abril de 2009, Exp. 17508.

Consejo de Estado, Sección Cuarta, Sentencia del 26 de octubre de 2009, Exp. 16761 y 16585.

Consejo de Estado, Sección Cuarta, Sentencia del 4 de marzo de 2010, Exp. 16531.

Revista de Derecho Fiscal n. ${ }^{\circ} 11 \cdot$ julio-diciembre de 2017 • pp. 7-51 
Consejo de Estado, Sección Cuarta, Sentencia del 29 de abril de 2010, Exp. 16891.

Consejo de Estado, Sección Cuarta, Sentencia del 19 de agosto de 2010, Exp. 16750 y 16236.

Consejo de Estado, Sección Cuarta, Sentencia del 10 de marzo de 2011, Exp. 17075.

Consejo de Estado, Sección Cuarta, Sentencia del 23 de junio de 2011, Exp. 17369.

Consejo de Estado, Sección Cuarta, Sentencia del 4 de agosto de 2011, Exp. 17628.

Consejo de Estado, Sección Cuarta, Sentencia del 5 de diciembre de 2011, Exp. 18327.

Consejo de Estado, Sección Cuarta, Sentencia del 23 de abril de 2009, Exp. 17508.

Consejo de Estado, Sección Cuarta, Sentencia del 11 de enero de 2012, Exp. 18599.

Consejo de Estado, Sección Cuarta, Sentencia del 1 de marzo de 2012, Exp. 17568.

Consejo de Estado, Sección Cuarta, Sentencia del 3 de marzo de 2012, Exp. 18135.

Consejo de Estado, Sección Cuarta, Sentencia del 12 de abril de 2012, Exp. 17734.

Consejo de Estado, Sección Cuarta, Sentencia del 24 de mayo de 2012, Exp. 18766.

Consejo de Estado, Sección Cuarta, Sentencia del 2 de agosto de 2012, Exp. 18696.

Consejo de Estado, Sección Cuarta, Sentencia del 18 de octubre de 2012, Exp. 18329.

Consejo de Estado, Sección Cuarta, Sentencia del 1 de noviembre de 2012, Exp. 18106.

Consejo de Estado, Sección Cuarta, Sentencia del 7 de diciembre de 2012, Exp. 18574.

Consejo de Estado, Sección Cuarta, Sentencia del 5 de septiembre de 2013, Exp. 18412.

Consejo de Estado, Sección Cuarta, Sentencia del 23 de enero de 2014, Exp. 19245

Consejo de Estado, Sección Cuarta, Sentencia del 27 De marzo de 2014, Exp. 18634.

Consejo de Estado, Sección Cuarta, Sentencia del 10 de julio de 2014, Exp. 19782.

Consejo de Estado, Sección Cuarta, Sentencia del 21 de agosto de 2014, Exp. 19412.

Consejo de Estado, Sección Cuarta, Sentencia del 12 de diciembre de 2014, Exp. 19261.

Consejo de Estado, Sección Cuarta, Sentencia del 21 de agosto de 2014, Exp. 19412.

Consejo de Estado, Sección Cuarta, Sentencia del 9 de abril de 2015, Exp. 19785.

Consejo de Estado, Sección Cuarta, Sentencia del 17 de abril de 2015, Exp. 16571.

Consejo de Estado, Sección Cuarta, Sentencia del 7 de mayo de 2015, Exp. 20580.

Consejo de Estado, Sección Cuarta, Sentencia del 6 de agosto de 2015, Exp. 20130.

Consejo de Estado, Sección Cuarta, Sentencia del 8 de octubre de 2015, Exp. 19495.

Consejo de Estado, Sección Cuarta, Sentencia del 12 de noviembre de 2015, Exp. 19999719708.

Consejo de Estado, Sección Cuarta, Sentencia del 13 de enero de 2016, Exp. 22165.

Consejo de Estado, Sección Cuarta, Sentencia del 4 de febrero de 2016, Exp. 20979. 
Consejo de Estado, Sección Cuarta, Sentencia del 2 de marzo de 2016, Exp. 19793.

Consejo de Estado, Sección Cuarta, Sentencia del 28 de junio de 2016, Exp. 18727.

Consejo de Estado, Sección Cuarta, Sentencia del 30 de agosto de 2016, Exp. 20591.

Consejo de Estado, Sección Cuarta, Sentencia del 8 de septiembre de 2016, Exp. 18945.

Consejo de Estado, Sección Cuarta, Sentencia del 15 de septiembre de 2016, Exp. 20555.

Consejo de Estado, Sección Cuarta, Sentencia del 4 de febrero de 2016, Exp. 20979.

Consejo de Estado, Sección Cuarta, Sentencia del 20 de enero de 2017, Exp. 20551.

Consejo de Estado, Sección Cuarta, Sentencia del 2 de febrero de 2017, Exp. 20517.

Consejo de Estado, Sección Cuarta, Sentencia del 1 de marzo de 2017, Exp. 21864.

Consejo de Estado, Sección Cuarta, Sentencia del 15 de junio de 2017, Exp. 21864.

Consejo de Estado, Sección Cuarta, Sentencia del 15 de julio de 2017, Exp. 20981.

Consejo de Estado, Sección Cuarta, Sentencia del 19 de julio de 2017, Exp. 20981. 